This is the author's final, peer-reviewed manuscript as accepted for publication. The publisher-formatted version may be available through the publisher's web site or your institution's library.

\title{
Altitudinal migration in bats: evidence, patterns, and drivers
}

Liam P. McGuire and W. Alice Boyle

\section{How to cite this manuscript}

If you make reference to this version of the manuscript, use the following information:

McGuire, L. P., \& Boyle, W. A. (2013). Altitudinal migration in bats: Evidence, patterns, and drivers. Retrieved from http://krex.ksu.edu

\section{Published Version Information}

Citation: McGuire, L. P., \& Boyle, W. A. (2013). Altitudinal migration in bats: Evidence, patterns, and drivers. Biological Reviews, 88(4), 767-786.

Copyright: (C) 2013 The Authors.

Biological Reviews (c) 2013 Cambridge Philosophical Society

Digital Object Identifier (DOI): doi:10.1111/brv.12024

Publisher's Link: http://onlinelibrary.wiley.com/enhanced/doi/10.1111/brv.12024/

This item was retrieved from the K-State Research Exchange (K-REx), the institutional repository of Kansas State University. K-REx is available at http://krex.ksu.edu 


\title{
Altitudinal migration in bats: evidence, patterns, and drivers
}

\author{
Liam P. McGuire ${ }^{*} \dagger$ and W. Alice Boyle ${ }^{\S}$
}

Advanced Facility for Avian Research, Department of Biology, University of Western Ontario, 1151 Richmond St. N, London, Ontario, Canada, N6A 5B7

*Author for correspondence (Email: 1.mcguire@uwinnipeg.ca; Tel.: (204) 786-9980; Fax: (204) 774-2401).

†Present address: Department of Biology, University of Winnipeg, 515 Portage Ave, Winnipeg, Manitoba, Canada, R3B 2E9

${ }^{\S}$ Present address: Division of Biology, Kansas State University, 307 Ackert Hall, Manhattan, Kansas, 66506, USA

Running head: Bat Altitudinal Migration

\begin{abstract}
Altitudinal migrations are common in all major vertebrate and some invertebrate lineages. Such migrations have important implications for the basic and applied ecology of animals making these movements. The idea that bats make altitudinal migrations has been suggested for nearly a century. However, studies documenting the existence and causes of altitudinal bat migrations are scarce, and are frequently published in the "grey" literature. For the first time, we comprehensively review the evidence supporting the existence of altitudinal bat migrations
\end{abstract}


worldwide, describe basic patterns of migration in temperate and tropical regions, and articulate and propose tests of hypotheses potentially explaining these migrations. We compiled a list of 50 studies indicative of altitudinal bat migration in 61 species (five families) from 21 countries (four continents). The temporal and spatial patterns of these migrations grouped biogeographically. Temperate bats generally exhibit sex-biased migrations with females inhabiting lower elevations than males during reproductive periods. Although there is less information on tropical bat migration, few studies report sex-biased migration. We compiled hypotheses proposed in the bat and (more extensive) avian literature to provide a list of hypotheses potentially explaining altitudinal bat migrations. These hypotheses rely upon temporal availability of (and competition for) food resources, spatial distribution of geomorphological features suitable for hibernation, sex-related differences in the use of torpor, mating opportunities, and climatic factors that impose direct physiological challenges to survival or that restrict the ability to forage. A more thorough description of the migration patterns of most species will be required to distinguish effectively among these hypotheses. We identify research avenues that would broaden our understanding of bat migration patterns and provide critical information required for effective conservation.

Key words: partial migration, differential migration, sexual segregation, bats, Chiroptera, evolution of migration, seasonal movements.

\section{CONTENTS}

I. Introduction

II. A brief review of bird altitudinal migration 
III. Evidence: do bats migrate altitudinally?

(1) Patterns: who, when, and where?

(a) Temperate patterns

(b) Tropical/sub-tropical patterns

IV. Drivers: why do bats migrate altitudinally and why do only some migrate?

(1) Asking the right questions

(2) Why do temperate bats migrate altitudinally?

(a) Why do (female) bats migrate downhill?

(b) Why do females not remain at low elevations year-round?

(c) Why do males often differ from females in migratory strategy?

(3) Why do tropical bats migrate altitudinally?

V. Taking bat altitudinal migration studies to new heights

VI. Conclusions

VII. Acknowledgements

VIII. References

\section{INTRODUCTION}

Interest in all aspects of bat migration has increased in recent years (Popa-Lisseanu \& Voigt, 2009). Migration has evolved independently in multiple lineages, and short- and long-distance migration likely evolved independently rather than sequentially (Bisson, Safi \& Holland, 2009). Current reviews of bat migration have used arbitrarily defined short- and long-distance movement thresholds that do not allow for the integration of even shorter distance movements (i.e. $<100 \mathrm{~km}$ ) into the theoretical and practical frameworks developed for longer-distance 
movements (Fleming \& Eby, 2003). However, consideration of these shorter-distance migrations, especially altitudinal migration, may lead to new insights into the evolution and maintenance of migratory systems. Altitudinal migration commonly refers to annual return movements of all or part of an animal population between breeding and non-breeding areas that differ in elevation (Dixon \& Gilbert, 1964; Rabenold \& Rabenold, 1985). Altitudinal migrations often occur over short spatial scales involving few physiological adaptations, and consequently, are frequently overlooked in studies of the causes and consequences of seasonal migrations. However, from the standpoint of understanding the underlying ecological and evolutionary factors influencing migratory decisions, these cyclical, seasonal movements parallel longerdistance latitudinal migrations in most important respects. They also pose similar challenges to devising effective species-level conservation strategies (Powell \& Bjork, 1995). Unfortunately, there is scant basic knowledge regarding the number of species that migrate altitudinally, the temporal and geographical patterns of such migrations, and the reasons for inter- and intraspecific variation in migratory tendency in most taxonomic groups. Altitudinal migrations have been reported from all continents except Antarctica, and in many terrestrial animal lineages including ungulates (Hebblewhite \& Merrill, 2009; Mysterud, 1999; Rice, 2008), carnivores (Loucks et al., 2003), lepidopterans (Haber \& Stevenson, 2004; Stefanescu, 2001), hymenopterans (Hunt et al., 1999), and many orders of birds (e.g. Johnson \& Maclean, 1994; Loiselle \& Blake, 1991; Ramos-Olmos, 1983; Sick, 1993). However, only in birds have altitudinal migration patterns and the factors driving these patterns been studied in detail, and even then in only a handful of species. Despite the fact that among bat researchers only relatively long-distance movements are commonly referred to as "migration", numerous sources mention seasonal altitudinal movements of bats around the world (e.g. Hutson, Mickleburgh \& Racey, 
2001). Yet close scrutiny of citations purportedly providing evidence for altitudinal bat migrations reveals that these papers often contain very weak evidence, and/or consist of conjecture and speculation. For instance, Sanborn \& Crespo (1957) is an oft-cited reference used to support the existence of altitudinal migration in South American hoary bats Lasiurus cinereus villosissimus. Yet the statement made by the authors (translated from Spanish) is simply: "It is possible that ... the Chilean individuals engage in altitudinal migrations, $\ldots$ and the Colombian and Venezuelan ones either altitudinal migration or no migration." (Sanborn \& Crespo, 1957, p. 10). Evidence backing this statement comes from nine specimens collected during the breeding season at lower elevations in Chile, a lack of records further north along the westward side of the Andes, and ten specimens collected from Colombia and Venezuela at various elevations [see Findley \& Jones (1964) for these data plotted on a map]. Note also that Sanborn \& Crespo (1957) presented the idea of altitudinal migration tentatively, using the word 'possible'. Thus, while it is plausible that hoary bats and other species do indeed engage in altitudinal migrations, a critical evaluation of the evidence is overdue.

Bats are ideally suited for comparative studies of migration evolutionary ecology. Like birds, they are small, endothermic, flying vertebrates. Thus, their behaviours have been independently shaped by many of the same morphological and physiological constraints as their better-studied avian counterparts. However, being mammals, they differ in some key respects that likely influence the trade-offs involved in migratory decisions: (i) bat embryos develop inside their mothers adding to the costs of flight during pregnancy; (ii) female bats incur substantial energetic costs of producing milk for nursing young; (iii) in some species, females store sperm (Crichton, 2000) which permits temporal and spatial asynchrony between mating (when sexes must be sympatric) and raising young (when sexes can be allopatric); and (iv) many 
species are capable of using torpor, greatly reducing energetic costs during inclement weather. These traits can explain both similarities and differences in results from the bird and bat literature investigating the physiological ecology and energetics of long-distance migrant species breeding in North America (McGuire \& Guglielmo, 2009; McGuire et al., 2011). The extent to which patterns of bat migration parallel or diverge from those of altitudinal migrant birds would considerably advance our understanding of the ecological and physiological factors that are important generally in shaping and driving altitudinal migration.

The objectives of this study are threefold: (i) compile and critically evaluate the evidence for bat altitudinal migrations via a thorough literature search; (ii) synthesize the hypotheses that could explain patterns in this body of literature, drawing from knowledge of the avian literature; and (iii) formulate a series of testable predictions to distinguish among the possible explanations potentially shaping these migrations. We hope that this review both clarifies the state of our knowledge of altitudinal bat migration and inspires more researchers to study this poorly understood topic. We begin with a brief review of the patterns and proposed drivers of altitudinal bird migration, using this as a basis for interpreting bat migrations.

\section{A BRIEF REVIEW OF BIRD ALTITUDINAL MIGRATION}

The study of migration in any taxonomic group and geographical area begins with documenting local seasonal fluctuations in abundance, and then identifying the spatial and temporal patterns of movements. These basic patterns must be elucidated before it is possible to answer questions regarding the ecological, physiological, and evolutionary causes and consequences of migration. In the avian literature, the first stages of this process began three-quarters of a century ago, and were primarily driven by monographs on bird distribution and abundance in a few tropical 
localities (e.g. Beebe, 1947; Skutch, 1967; Slud, 1964). Earlier references to altitudinal migrations in temperate-zone mountains (e.g. Grinnell \& Miller, 1944; Presnall, 1935) failed to attract the interest that their tropical counterparts did, perhaps because the seasonal disappearance of birds from frigid temperate mountains was less surprising to temperate-zone biologists than was the seasonal movement of birds up and down tropical mountains. The majority of the literature on avian altitudinal migration still consists of documenting patterns consistent with the occurrence of altitudinal migration obtained via direct observations (e.g. Ferrari et al., 2008), mark-recapture data derived from mist-netting and banding (e.g. Burgess \& Mlingwa, 2000), or more recently, stable isotope data (e.g. Fraser, Kyser \& Ratcliffe, 2008; Hobson et al., 2003) and radio-tracking (Powell \& Bjork, 2004). These data come primarily from the northern Neotropics [especially Costa Rica (Stiles, 1988) and Mexico (Ornelas \& Arizmendi, 1995)], Brazil (Alves, 2007; Bencke \& Kindel, 1999), South Africa (Johnson \& Maclean, 1994; Symes, Wirminghaust \& Downs, 2002), and to a lesser extent temperate North America (Morrissey, Bendell-Young \& Elliott, 2004; Rabenold \& Rabenold, 1985), Europe (Saniga, 1995), Australasia (Green, 2006), and other parts of South America (Hilty, 1997). Evidence for altitudinal bird migration now exists for most major mountain ranges of the world.

Relatively few avian systems have been sufficiently well characterized to permit studies aimed at understanding why and how these migrations occur, and why they occur in some but not all taxa living in a particular region. The proposed causes of altitudinal migration involve spatial and temporal variation in food availability (Levey \& Stiles, 1992; Rabenold \& Rabenold, 1985), predation risk (Boyle, 2008a), nest-site limitation (Mackas et al., 2010), or climatic conditions (Boyle, Norris \& Guglielmo, 2010; Skutch, 1969). More than one factor may contribute to shaping migration patterns. For instance, different factors likely govern uphill and 
downhill portions of the migration cycle in many species because the factors making one elevation suitable for reproduction may not make it the best elevation for survival during the non-breeding season.

The costs and benefits of alternative migratory strategies have been studied in detail in only a handful of bird species including American dippers Cinclus cinclus in Pacific coastal mountains of Canada (Gillis et al., 2008; Mackas et al., 2010; Middleton \& Green, 2008; Middleton, Morrissey \& Green, 2006; Morrissey, 2004), and white-ruffed manakins Corapipo altera in wet tropical forested mountains in Costa Rica (Boyle, 2008b, 2010; Boyle et al., 2010, 2011; Rosselli, 1994). Because these species serve as a reference for comparisons with tropical and temperate bat species, we briefly describe the major aspects of these migrations.

American dippers range from Alaska to Central America in western mountains, feeding on fish fry and aquatic invertebrates (Willson \& Kingery, 2011). Populations in southern British Columbia consist of resident individuals that breed and over-winter on low-elevation rivers, and migrant individuals that breed along high-elevation streams, descending to low-elevation rivers to over-winter with residents (Morrissey et al., 2004). Migrants have access to inferior food resources during the breeding season which results in poorer nestling condition (Mackas et al., 2010). Migrants also experience similar rates of nest predation relative to residents (Morrissey, 2004). Residents initiate nesting earlier each year, are more likely to rear a second brood, and consequently raise more young (Morrissey, 2004). Despite slightly lower annual survival, residents achieve greater lifetime reproductive success (Gillis et al., 2008). The most plausible hypothesis explaining altitudinal migration in this species is that competition for food and/or limited breeding territories forces some individuals to breed at higher-elevation (inferior) sites 
that are unsuitable for year-round residency due to climatic factors that not only pose direct physiological challenges to survival but make access to food impossible.

Migration patterns of frugivorous white-ruffed manakins living in the mountains of Central America contrast with American dippers in many regards. Costa Rican Caribbean-slope populations of this species consist of residents that remain at montane breeding sites year-round and migrants that breed together with residents, but then migrate downhill, spending a few to several months of the non-breeding season at low elevations (Rosselli, 1994). Breeding location and timing coincides with maximum food availability, but food availability cannot explain downhill migration (Boyle, 2010). Migration is male-biased and related to condition (Boyle, 2008b). Higher-elevation breeding sites receive twice as much rain and more severe rain storms than the adjacent lowlands. Males that remain at high elevations year-round suffer more severe adverse effects of storms (Boyle et al., 2010), but accrue reproductive advantages via increased social status and the ability to attract females the following year (Boyle et al., 2011). The most plausible hypothesis explaining altitudinal migration in this species is that montane rainstorms force energetically challenged individuals downhill via limited foraging opportunities during storms with consequent survival benefits and reproductive costs.

The two species' migrations described above exemplify some general patterns evident in the broader avian literature. First, climatic differences between high and low elevations play a role in shaping migration patterns. Second, among tropical altitudinal migrants, most species are frugivorous or nectarivorous, an observation that initially led to several tests of food-based hypotheses explaining tropical altitudinal migration (Chaves-Campos, 2004; Rosselli, 1994; Solórzano et al., 2000). Third, interactions between environmental conditions and individual physiology shape migratory decisions: in neither American dippers nor white-ruffed manakins 
does food availability, predation risk, or climate affect migration tendency in simple, straightforward ways. Finally, partial migration (only a portion of the population migrates) or differential migration (demographic groups migrate different distances) are common among avian altitudinal migrants and are often sex-biased (Johnson \& Maclean, 1994; Stiles, 1988). This last point implies that facultative migration decisions can mediate life-history trade-offs in a dynamic fashion. Such flexible migration systems are thus particularly valuable for identifying ecological factors leading to the evolution of migratory behaviour in general. After presenting what is known of bat altitudinal migration patterns, we will return to these generalities and examine the extent to which the processes apparently shaping avian altitudinal migration may also shape bat altitudinal migration.

\section{EVIDENCE: DO BATS MIGRATE ALTITUDINALLY?}

Despite frequent mention of altitudinal migration in the bat literature, few studies have focused on these movements explicitly. Several studies have examined changes in bat communities with elevation (e.g. McCain, 2007) but treat altitudinal distribution as a fixed trait of species or populations, ignoring possible seasonal movements. Much of the literature pertaining to altitudinal bat migration is anecdotal or speculative, and is found in regional journals or grey literature sources. Furthermore, altitudinal migration is rarely referred to as such in the bat literature. More frequently, authors refer to seasonal distributional shifts, seasonal invasions, elevational movements, altitudinal shifts, or sexual segregation. Thus, we began by conducting a thorough literature search using standard online search engines (i.e. Web of Science, Google Scholar) for evidence of altitudinal migration by bats worldwide. We started with reviews of bat migration (e.g. Fleming \& Eby, 2003; Griffin, 1970; Hutterer et al., 2005) and followed chains 
of references from those sources to expand our database. This effort produced 50 papers that contained evidence, discussion, or speculation regarding altitudinal migrations in 61 species of bats belonging to five families (Table 1). These reports came from around the world (i.e. North America, Central and South America, Eastern and Western Europe, Asia, Pacific Islands) and were published in English, Spanish, Portuguese, French, German, and Chinese. We may have missed relevant literature from Asia, Africa, Eastern Europe, and elsewhere if such sources were not referenced by other authors, were not discoverable via our search methods, or due to linguistic limitations of the authors.

\section{(1) Patterns: who, when, and where?}

Two broadly different patterns of altitudinal migration emerge from this literature. The first pattern was common in temperate species, while the second was generally (but not exclusively) associated with tropical or sub-tropical species. Accordingly, we deal with these groups separately below. Where temperate/tropical categorization was ambiguous, we discuss those species based on ecological and phylogenetic affinities. For example, the lesser long-nosed bat Leptonycteris yerbabuenae, a nectarivore (Family Phyllostomidae), ranges from Mexico north to southern Arizona. The populations reaching Arizona migrate altitudinally in patterns resembling those of tropical species, and hence, we discuss this species together with species making similar migrations.

\section{(a) Temperate patterns}

The idea that temperate bats migrate altitudinally dates back a century. The very first article published in the Journal of Mammalogy (volume 1, issue 1, page 1; Allen, 1919) describes the 
possibility of a "local and seasonal invasion by the non-breeding individuals" of "the upper levels of mountains". A year earlier, upon finding only female and young Yuma myotis Myotis yumanensis at lower elevations, Grinnell (1918) suggested that in summer, non-breeding males may move to higher elevations to forage. However, neither of these authors provided direct evidence of altitudinal bat migration. Today, several studies provide convincing evidence of altitudinal migration in temperate regions. One of the best examples comes from big brown bats Eptesicus fuscus in Colorado. Radiotracking bats between summer and winter roosts, Neubaum, O'Shea \& Wilson (2006) confirmed that bats (primarily females) migrate to lower elevations for the summer and return uphill to the mountains to hibernate in winter. Similarly, band recoveries of Townsend's big-eared bats Corynorhinus townsendii in the Black Hills of South Dakota indicate that females migrate from high-elevation hibernacula to low-elevation summer roosts (Cryan, Bogan \& Altenbach, 2000). Sex-biased differential altitudinal migration has also been suggested for little brown bats Myotis lucifugus in the Rocky Mountains, Alberta, Canada (Barclay, 1991). Likewise, Daubenton's bat Myotis daubentonii in Switzerland migrate downhill in the spring and return uphill in autumn, presumably to high-elevation hibernacula (Leuzinger \& Brossard, 1994). All females in this Swiss population appear to migrate, whereas males are partially migratory with some individuals remaining at high elevations throughout the summer with similar patterns in M. daubentonii living in England (Senior, Butlin \& Altringham, 2005), Italy (Russo, 2002), Germany (Encarnação et al., 2005), and Slovakia (Kaňuch \& Krištín, 2006).

Many bat species around the world hibernate at higher elevations than where they rear their young: Corynorhinus townsendii in Utah, USA (Szewczak et al., 1998), lesser horseshoe bats Rhinolophus hipposideros in Austria (Hutterer et al., 2005), and three species of Taiwanese 
vespertilionid bats (Cheng, 2009; Cheng, Fang \& Chou, 2010; Cheng et al., 2009). In each of these cases, it is not yet known whether only females or both sexes make altitudinal migrations.

In California, USA, male western red bats Lasiurus blossevilli (Grinnell, 1918) and hoary bats Lasiurus cinereus (Vaughan \& Krutzsch, 1954) apparently migrate locally to higher elevations in summer from low-elevation over-wintering sites while females remain at low elevations year-round. Other individuals (of this and other species) migrate latitudinally, yet like the California populations, the sexes segregate altitudinally in summer. In South Dakota, male $L$. cinereus and silver-haired bats Lasionycteris noctivagans (both latitudinal migrants) are more common at high elevations than females, suggesting that following latitudinal migrations, males settle at higher elevation than females (Cryan et al., 2000). Without more detailed knowledge of the migratory movements of these populations it is unclear whether sexual segregation during the summer months is analogous to the altitudinal migrations in other populations.

Most of these temperate-breeding species exhibit sex-biased migration resulting in females occurring at lower elevations than males during the summer resulting in altitudinal sexual segregation. Altitudinal sexual segregation is common in temperate bat communities (e.g. Baker \& Lacki, 2004; Constantine, 1967; Easterla, 1973; Fenton et al., 1980; Grindal, Morissette \& Brigham, 1999; Holzhaider \& Zahn, 2001; Howell, 1920; O'Shea et al., 2011a, b; Thomas, 1988). In each of these examples, adult males (and sometimes non-breeding females) are found at higher elevations while reproductive females predominate at lower elevations. The majority of the species considered in these reports would normally be considered regional migrants (e.g. Myotis lucifugus, Myotis myotis) although others are typically characterized as sedentary (e.g. Eptesicus fuscus) or long-distance latitudinal migrants (e.g. Lasiurus cinereus, Nyctalus leisleri; 
Fleming \& Eby, 2003). Because sexes must occur sympatrically to mate, species or populations with altitudinal sexual segregation likely represent additional partial altitudinal migrants.

\section{(b) Tropical/sub-tropical patterns}

Compared to the abundant circumstantial and anecdotal evidence for altitudinal migration in temperate bats, there are few data documenting altitudinal movements in tropical or sub-tropical regions. Studies of community composition changes across altitudinal gradients are fairly common [e.g. McCain (2007) and references therein], but study designs typically have not included seasonal dimensions capable of detecting altitudinal migrations (but see SánchezCordero, 2001). Other reports refer to the possibility of altitudinal migration, but provide no evidence. For example, Hutson (2002) mentions that Pteropus giganteus might migrate up and down the Himalayas, and Fraser, McKinnon \& Diamond (2010) attempted to document altitudinal bat migration using stable isotopes in Nicaragua but problems of small sample sizes resulted in ambiguous conclusions.

A handful of studies provide evidence of altitudinal bat migration in tropical regions. In Costa Rica, long-term capture records at a montane site reveal that several species are either completely absent for part of the year or show substantial seasonal changes in abundance: the great fruit-eating bat Artibeus lituratus, Toltec fruit-eating bat Artibeus toltecus, silky shorttailed bat Carollia brevicauda, little yellow-shouldered bat Sturnira lilium, and Underwood's long-tongued bat Hylonycteris underwoodi (Timm \& LaVal, 2000). These authors suggested that seasonal changes in abundance may represent altitudinal migration, as is common among birds at the same site (Chaves-Campos, 2004; Powell \& Bjork, 1995). Similarly, altitudinal migration has been proposed to explain variation in seasonal abundances of S. lilium and hairy yellow- 
shouldered bats Sturnira erythromos in the Argentinian Andes (Giannini, 1999). Notably, neither of these studies makes any mention of biased sex ratios in contrast to studies of temperate bat communities.

A study in Brazil (Esbérard et al., 2011) conducted extensive year-round sampling at multiple elevations to test for evidence of altitudinal migration in Ipanema broad-nosed bats Pygoderma bilabiatum. In regions where temperature varied seasonally $P$. bilabiatum was absent, or less common, at higher elevations during cooler seasons. The authors concluded that bats migrated altitudinally in response to seasonal climate variation, a conclusion supported by constant abundance in regions where climate did not vary substantially. Sex ratio was femalebiased at higher elevations suggesting that males remained at lower elevations.

Perhaps the best example of altitudinal bat migration in tropical or sub-tropical regions is that of the lesser long-nosed bat Leptonycteris yerbabuenae (Cockrum, 1991). In the northern parts of this species' range (i.e. NW Mexico and SW USA), L. yerbabuenae migrate latitudinally. However, altitudinal migration also appears to play a prominent role in the movements of this species during the summer. Reproductive females migrate northward in the spring (late March early May), foraging at lower elevations on seasonally abundant flowers from columnar cacti. When pups become volant in mid-summer (June-July), females and young move to higher elevations (Cockrum, 1991). These migrations are sex-biased; males (and non-reproductive adult females) remain in the southern portion of the range until mid summer (June-July) following which they join the reproductive females at the northern high-elevation sites (Cockrum, 1991) before all returning south in the autumn (September-October). In some southerly breeding populations of L. yerbabuenae (i.e. Puebla and Oaxaca, Mexico) individuals are hypothesized 
only to migrate altitudinally (Herrera-Montalvo, 1997; Rojas-Martínez et al., 1999; ValienteBanuet et al., 1996, 1997).

South American hoary bats Lasiurus cinereus villosissimus also likely migrate altitudinally. Sanborn \& Crespo (1957) analyzed the location and timing of collections of L.c. villosissimus and interpreted plausible movement patterns based on those records. Based on seasonal absence from the Chilean lowlands, the proximity of those records to the Andes, and the wide altitudinal distribution of records from Colombia and Venezuela, Sanborn \& Crespo (1957) suggested that L.c. villosissimus make altitudinal migrations on the western slopes of the Andes in Chile and northern S. America. This study was among the first to explicitly suggest that bats make altitudinal migrations and is frequently cited as evidence for altitudinal bat migration despite the aforementioned tentative wording in the original publication (see Section I).

On the Galapagos Islands, altitudinal migration may explain the temporal and spatial distribution of L.c. villosissimus and Galapagos red bats Lasiurus blossevillii brachyotis. Capture data for L.b. brachyotis revealed a female sex bias in the lowlands and male sex bias at high elevations during the cool season (McCracken et al., 1997). Acoustic sampling of both species provides evidence of a seasonal increase in activity in the lowlands during the cool season consistent with females migrating to higher altitudes during the hot (breeding) season when heavy rainstorms are more frequent (McCracken et al., 1997). Similarly, on the island of Hawai $i$, visual observations, capture records, and acoustic monitoring reveal that Hawaiian hoary bats Lasiurus cinereus semotus migrate to higher elevations, above the cloud inversion layer, during the non-breeding season when rainfall peaks (Bonaccorso et al., 2008; Menard, 2001; Pinzari, Bonaccorso \& Gorresen, 2009). This pattern appears to be more pronounced on the windward (wetter) side of the island and may be protandrous. Menard (2001) noted an even 
sex ratio in the lowlands during the breeding period, followed by a female bias in the postbreeding period suggesting the males migrate upslope in advance of females. On the leeward (drier) side of the island, bats remain common at lowland sites year-round, although activity increases at dry, high-elevation sites early in the rainy season (Bonaccorso et al., 2008).

\section{DRIVERS: WHY DO BATS MIGRATE ALTITUDINALLY AND WHY DO ONLY SOME MIGRATE?}

\section{(1) Asking the right questions}

As the previous section demonstrates, the patterns of altitudinal bat migration can be relatively complex. In most cases it is likely that several factors contribute to shaping these patterns. Understanding the underlying ecological and evolutionary causes of bat migration patterns requires that we answer two related but distinct questions. The first question is why do bats migrate at all (i.e. why do they not just stay in the same location year-round?). In reality, this is better posed as two questions: why do bats migrate uphill, and why do they migrate back down? Seemingly straightforward explanations for movements in one direction may not explain return movements in the opposite direction. The other related question, is why do only some individuals (typically one sex) in a population or species migrate, or migrate different distances than the others? To fully explain migratory patterns, hypotheses must address both questions. Ultimately, hypotheses explaining migration rely on variation in few ecological factors, including food availability, physiological (especially energetic) consequences of weather, predation risk, habitat limitation, and/or competition for mates.

Food availability and competition for food underlie most explanations for migration in many taxa from fish (Gross, Coleman \& McDowall, 1988), to mammals such as giant pandas 
Ailuropoda melanoleuca (Loucks et al., 2003), to birds (Cox, 1968; Fretwell, 1980). If food drives altitudinal migration, animals should move to elevations of highest relative food availability - a prediction that does not necessarily lead to animal abundances tracking food abundances at a given location over time. Under some circumstances, abundant food is not "available" due to territoriality (Fretwell, 1972), increased threat of predation (Rosenzweig \& Abramsky, 1997), or inclement weather (Boyle et al., 2010). When different sex and age groups form dominance hierarchies, food limitation as influenced by competition can lead to differences in altitudinal migration strategies among demographic groups (Ketterson \& Nolan, 1976).

Physiological and energetic costs of cold temperatures undoubtedly influence migration patterns both generally and in altitudinal migrations specifically, especially in temperatebreeding species. Endothermic flying vertebrates incur both high energetic costs of surviving when temperatures drop below their thermal neutral zone, as well as high costs of carrying extra body mass in the form of fuel reserves to buffer against inclement weather. Small body size exacerbates these energetic challenges due to increasing heat loss per unit mass as body size declines (Calder, 1974). When sexes differ in body size, the energetic (fasting) consequences of these differences can help explain differences in migratory strategies among sexes (Ketterson \& Nolan, 1976). In some bats, hibernation and use of daily torpor greatly reduce energetic costs during periods of inactivity. With decreasing ambient temperature, the potential energy savings of using torpor increase, but the cost to rewarm to normal body temperature also increases [see Speakman \& Thomas (2003) for a discussion of the consequences of ambient temperature on torpor energetics]. Therefore, the net energetic benefits of migration to areas with lower temperatures will depend on numerous factors related to torpor energetics such as the frequency 
of arousal, endogenous energy stores, roost microclimate, and the potential for passive rewarming.

Another factor hypothesized to affect migratory decisions in birds is temporal and spatial variation in predation risk (Boyle, 2008a; Greenberg, 1980; Lank et al., 2003). Predation risk is generally not perceived as a major factor influencing bat evolutionary ecology (Barclay \& Harder, 2003), although it is possible that, like nestling birds, pups are more susceptible to predators than adults, and females locate their maternal roosts accordingly. Without specific knowledge of the identity, distribution, and relative abundance of such predators, however, it is impossible to evaluate predictions based on a predation-based hypothesis for bats.

Limited availability of critical and patchily distributed habitats may also shape altitudinal migration patterns. Habitat requirements may vary seasonally, being associated with only breeding or overwintering. One critical habitat is a suitable hibernaculum, required by nonmigratory temperate breeding bats. A difference in the elevation of critical habitats required at different times of year could explain part of the altitudinal migratory cycle.

Mate competition can shape altitudinal migration patterns via differences among individuals in the reproductive payoffs of different migratory decisions (Boyle et al., 2011; Morbey \& Ydenberg, 2001). Because female bats of some species can store sperm for many months (Crichton, 2000), any trait that enables males to gain reproductive advantages (possibly by being the first male a female mates with or having a longer period over which to mate repeatedly) may affect the timing and location of migration. This implies that even if food or climatic factors drive females to migrate altitudinally, males may also make those movements (although not necessarily at the same time as females) solely for reproductive reasons. 
Altitudinal migration patterns can be explained by one or more of these basic underlying ecological factors (Cristol, Baker \& Corbone, 1999). Below we evaluate what is known of temperate and tropical bat altitudinal migration in light of these potential drivers.

\section{(2) Why do temperate bats migrate altitudinally?}

(a) Why do (female) bats migrate downhill?

In that first Journal of Mammalogy paper, Allen (1919) suggested that females were not found at high elevations during the summer because reproductive demands constrained them to “their proper 'life zone'". Numerous authors have echoed Allen's (1919) speculation in various versions of a hypothesis that we refer to as the "reproductive constraints hypothesis". This hypothesis combines food limitation and physiological consequences of weather by proposing that the energetic demands of pregnant and lactating females (Kurta et al., 1989) prevent them from inhabiting higher elevations where temperatures are cooler and insect prey are less abundant or more variable (Cryan et al., 2000). Wetter, cooler weather is associated with reduced food supply and reduced reproductive success (fewer reproductive females, delayed parturition dates, females in poor body condition) in insectivorous bats (Grindal, Collard \& Brigham, 1992; Lewis, 1993). The reproductive constraints hypothesis proposes that the energetic challenges of cool temperatures and reduced prey availability represent two distinct but correlated factors.

Males may be able to inhabit higher elevations by using torpor to save energy when temperature is low and/or food is in short supply. However, lowering body temperature has detrimental effects on foetal development (Cryan \& Wolf, 2003; Grinevitch, Holroyd \& Barclay, 1995; Willis, Brigham \& Geiser, 2006) restricting torpor use in pregnant females. Although females may use torpor at the expense of longer gestation (Racey, 1973; Racey \& Swift, 1981), increases 
in gestation time may be constrained by consequent reductions in time available for young to develop and acquire energy reserves to survive winter hibernation at temperate latitudes where the active season is short. Furthermore, in some foliage-roosting species, precocial young are left exposed in the roost while the mother forages. The limited thermoregulatory capacity of newborn pups (Klug \& Barclay, in press) means that warmer temperatures at low elevations may increase pup survival.

The reproductive constraints hypothesis predicts sexual segregation during the breeding season, with pregnant and lactating females found at lower elevations and males and nonreproductive females at higher elevations. The migration and sexual segregation patterns elucidated thus far of Eptesicus fuscus (Neubaum et al., 2006), Myotis lucifugus (Barclay, 1991), Myotis daubentonii (Russo, 2002; Senior et al., 2005), and many other temperate species (e.g. Cryan, 2003) are consistent with the reproductive constraints hypothesis. However, food availability can apparently mitigate the physiological challenges of cold. In the Canadian Rocky Mountains, reproductive females of $M$. lucifugus leave high elevations in summer, but female long-eared myotis Myotis evotis remain at high elevations year-round (Barclay, 1991). Due to differences in foraging behaviour, more prey is available for M. evotis than M. lucifugus. Higher relative food availability may provide the additional energy required to enable female M. evotis to maintain normothermic body temperatures and successfully reproduce at higher elevations despite cooler temperatures.

An hypothesis similar to the reproductive constraints hypothesis has been proposed to explain the absence of reproductive females of several species from high elevations of coastal (but not interior) mountain ranges of the NW United States (Thomas, 1988). High-elevation coastal sites receive more (and more frequent) summer rain than interior sites. Summer rain 
could limit the foraging opportunities for insectivorous bats, especially energetically challenged reproductive females. Under this variation of the reproductive constraints hypothesis, it is not the direct physiological effects of temperature, but rather climatic factors affecting foraging opportunities that lead to downhill migrations in some populations. This hypothesis is virtually identical to the limited foraging opportunities hypothesis proposed to explain white-ruffed manakin migration (Boyle, 2008b).

It is clear that high elevations of temperate mountains often experience weather and/or food availability incompatible with rearing offspring, and this fact likely drives the downhill migration of reproductive females to lower elevations during summer. Theoretically, weather and food availability could act independently. In practice, however, it is difficult to imagine how this might occur for temperate insectivorous species. Because aerial insect prey abundance is closely tied to weather, climatic conditions that would preclude foraging (rain, wind, cold) would also affect the abundance of prey, thus confounding the two hypotheses. One approach to distinguish between these hypotheses would be to determine patterns of altitudinal sexual segregation in a species whose prey and foraging activities are unaffected by short-term weather fluctuations. The reproductive constraints hypothesis would predict female-biased migration irrespective of food availability whereas the food availability and limited foraging opportunities hypotheses would predict no downhill migration. This prediction, in combination with associations between migratory tendency and both food and short- and longer-term variation in climatic variables could elucidate the underlying causes of female-biased downhill migration.

(b) Why do females not remain at low elevations year-round? 
At least two hypotheses could explain why females migrate back uphill following reproduction. First, because all bats that remain in temperate regions year-round hibernate, uphill movements may function to locate suitable hibernacula. This hypothesis relies on habitat limitation to explain the uphill portion of the migratory cycle. Subterranean sites such as caves and abandoned mines are not uniformly distributed with respect to elevation, and many studies report hibernacula to be abundant in mountainous areas (Barclay, 1991; Cryan et al., 2000; Piksa, 2008; Piksa, Bogdanowicz \& Tereba, 2011; Schowalter, 1980; Szewczak et al., 1998). Furthermore, cave temperature is partially determined by mean annual surface temperature which varies with altitude (Barry, 2008). Consequently, bats may migrate to caves at elevations where optimal temperature conditions are found. Several authors have suggested that short altitudinal migrations are all that would be necessary for female bats to move between suitable summer and winter habitats (Barclay, 1991; Cryan et al., 2000; Neubaum et al., 2006).

An alternative hypothesis for the return of females uphill relies on the phenology of food resources along elevational gradients. With increasing elevation, peak plant and insect productivity shifts temporally. Advancing phenological peaks are thought to explain ungulate migration in temperate mountains (Mysterud et al., 2001; Sawyer \& Kauffman, 2011). Although this hypothesis has received little attention in the bat literature (but see brief mention in Pierson, Rainey \& Corben, 2001) prey phenology could potentially contribute to both tropical and temperate altitudinal bat migrations, and warrants further investigation.

The hibernacula availability and food phenology hypotheses for autumn uphill migration in females make several contrasting predictions. A critical prediction of the hibernacula availability hypothesis is that in areas where bats migrate altitudinally, suitable hibernacula are not found at lower elevations. The food phenology hypothesis predicts that females would spend at least a 
few weeks foraging at high elevations prior to entering hibernacula, and that food availability during the pre-hibernation period is higher at higher elevations than at lower elevations. Such patterns should result in measurable differences in behavioural and physiological metrics reflective of fueling rates in bats foraging at high and low elevations (e.g. duration of foraging bouts, rates of mass gain, and concentrations of plasma triglycerides). If food phenology does not affect migratory patterns and migration is driven by the availability of hibernacula, then we would predict females to proceed directly to hibernacula upon upslope migration.

(c) Why do males often differ from females in migratory strategy?

There are at least three plausible explanations why male bats frequently adopt different migratory strategies than their female counterparts. These explanations in turn rely upon climatic effects on energetic strategies, competition for mates, and intra-specific competition for food.

The fact that pregnant females incur high costs (via foetal development) of torpor use relative to males may explain why females, but not males, migrate to lower elevations while males remain at higher elevations (the 'low-maintenance male' hypothesis; Weller, Cryan \& O'Shea, 2009). In addition to mitigating the effects of bad weather, torpor may benefit males by limiting energy expenditures during inactive periods, resulting in a greater net energy gain for a given foraging effort (Speakman \& Rowland, 1999). This energetic benefit has been suggested to explain migration or sex-ratio patterns in several studies (Barclay, 1991; Grindal et al., 1999; Russo, 2002). Non-reproductive females are presumably subject to similar energy demands as males and thus are also predicted to occur at higher elevations. Cryan et al. (2000) found a higher proportion of non-reproductive females at higher elevations, but other studies (e.g. Grindal et al., 1999; Leuzinger \& Brossard, 1994) have found both reproductive and non- 
reproductive females at lower elevations. In addition to energetic benefits, increased torpor use at higher elevations may reduce predation risk if predation risk is greater during foraging than roosting (Grinevitch et al., 1995; a.k.a., the 'cautious male' hypothesis, Weller et al., 2009).

In birds, one factor hypothesized to lead to differential migration is sexual size dimorphism (Belthoff \& Gauthreaux, 1991). Individuals of the larger sex are better able to endure the harsher climate at higher altitudes (or latitudes) because of the lower surface area to volume ratio. In vespertilionid bats females tend to be larger than males (Williams \& Findley, 1979) thus predicting differential male-biased altitudinal migration, opposite to observed patterns. Sexual size dimorphism in bats may predispose males to being more heterothermic (increased torpor use, an option not typically available to birds) at cooler high altitudes. Conversely, larger body size in females may be a result of selection for homeothermy during pregnancy (Williams \& Findley, 1979) which would require the warmer temperatures of low elevations if food availability is not sufficient to support the higher energetic demands of maintaining normothermia at high altitudes. Thus, while size dimorphism may be an important factor in explanations of both bird and bat altitudinal migration, the ability of bats to use torpor (and the benefits of homeothermy in pregnant females) may have resulted in reversed patterns of sexbiased migration in species with similar patterns of sexual size dimorphism.

A second hypothesis proposed to explain why many males spend the summer at high elevations relies on mate competition. For many populations that hibernate at high-elevation sites, mating occurs at hibernacula (associated with a behaviour known as "swarming"; Fenton, 1969; Piksa, 2008; Piksa et al., 2011). Males remaining at high elevations throughout the summer may gain access to females earlier upon return to hibernation sites. This hypothesis seems unlikely to be the sole explanation for sexual segregation as the short distances involved 
in altitudinal migration are likely traversed rapidly. Males could live at low elevations in summer and merely migrate in advance of females to gain earliest access to females. Using microsatellite markers to assign probability of paternity, Senior et al. (2005) demonstrated that M. daubentonii pups were more likely to be fathered by males spending summer months at low elevation - a result consistent with mate competition driving male altitudinal migrations. However, given the random and promiscuous mating system of some hibernating species (Thomas, Fenton \& Barclay, 1979), it is unclear how early access to females might provide a reproductive advantage. Further research into post-copulatory mechanisms and other factors affecting mating success is required to elucidate further the plausibility of this hypothesis.

A variation of the mate competition hypothesis could explain migration patterns of populations that do not hibernate at high elevations, but migrate latitudinally in addition to altitudinally (e.g. Lasiurus cinereus and Lasionycteris noctivagans in North America). Some males apparently migrate latitudinally (as do females) but settle at higher elevations upon reaching their summering grounds (e.g. Cryan et al. 2000). Mating occurs in the autumn (Kunz, 1982; Shump \& Shump, 1982) and we know of no evidence of altitudinal migration in females of these species. Thus, if the males migrate downhill prior to southward migration, they could gain access to reproductive females earlier than would males that summered further south (similar to the situation described for M. daubentonii by Senior et al., 2005). However, some male L. cinereus that over-winter in California migrate to "certain boreal 'islands' in some of the higher mountain ranges" (Vaughan \& Krutzsch, 1954, p. 432), foregoing the latitudinal component of their migratory cycle. Male altitudinal migration in this Californian population is not consistent with the mate competition hypothesis because females are thought to spend the summer elsewhere (Cryan, 2003). One intriguing possibility warranting investigation is that the 
decision made by males whether or not to migrate latitudinally (potentially permitting early access to mates) may be mediated by individual condition. Under this scenario, only males able to maintain better body condition would migrate latitudinally with the females, while lowerquality males would forego early mating opportunities, migrating altitudinally and saving energy by increased torpor use (as described above). If this is the case, it would present strong parallels (and interesting variations) to white-ruffed manakins where altitudinal migration mediates a trade-off between factors affecting survival and reproduction (Boyle et al., 2011).

A third explanation for variation in strategy between males and females is competition for food (a.k.a., the 'submissive male hypothesis'; Weller et al., 2009). Under this hypothesis, low elevations provide superior foraging conditions but reproductive females and/or dominant males competitively exclude subordinate males who then are restricted to inferior higher elevations (Encarnação et al., 2005; Menard, 2001; Russo, 2002; Senior et al., 2005). This hypothesis is similar to that proposed to explain the movements of American dippers (Mackas et al., 2010). In both the birds and bats, lower quality individuals are "forced" up to higher elevations, making the best of a bad deal. Although territoriality is rarely documented in bats, and aerial invertebrate prey resources are difficult to defend, lack of research on this topic may contribute to the paucity of evidence for territoriality. It is noteworthy that most bat species for which competition for food is a proposed cause of differential migration also forage in aquatic habitats as do dippers (Encarnação et al., 2005; Leuzinger \& Brossard, 1994; Russo, 2002; Senior et al., 2005). Foraging in these spatially restricted aquatic habitats may thus be a trait that leads to competition for food, thereby indirectly shaping migration patterns. Such an explanation may also explain sex biases observed in riparian habitats in British Columbia, Canada (Grindal et al., 1999). An alternative hypothesis that would result in the same observed patterns is that males altruistically 
remain in sub-optimal habitat, leaving the higher quality foraging sites for pregnant females and juveniles (a.k.a., the 'facilitating male' hypothesis; Weller et al., 2009). The promiscuous mating system of swarming bat species (e.g. Thomas et al., 1979) and the limited interactions between males and females that would result from altitudinal segregation imply that such altruistic explanations are unlikely (Wilkinson, 1987).

The food competition hypothesis could act in combination with the mate competition hypothesis. Males summering at low elevations (perhaps having out-competed subordinate males who were then forced to remain at high elevations) may have access to superior foraging areas. Better foraging could result in better body condition (Russo, 2002; Senior et al., 2005) which may then result in increased mating success when competing with high-elevation males (Senior et al., 2005). However, it remains to be determined whether the increased mating success results from earlier access to females, from better body condition due to superior foraging opportunities, or some other underlying factor that enables them to out-compete subordinate males. A caveat here is that mass differences inferred to reflect body condition between males summering at high and low elevations (i.e. lower mass of bats at high elevations) may result from a facultative and adaptive reduction of body mass functioning to reduce wing loading, thus decreasing flight costs and increasing manoeuvrability (Boyle, Winkler \& Guglielmo, 2012; Russo, 2002).

Many testable predictions can discriminate among competing hypotheses for why males often differ from females in their migration patterns. The torpor and energetics hypotheses predict that all males should remain at high elevations in the absence of females. If competition for low-elevation food resources explains male migration patterns, those that migrated to low elevation should arrive at swarming sites in better condition than those that remain at high elevations year-round. The opposite would be true if males remain at high elevation for the 
energetic benefits of increased torpor use. If competition for food or mates drives downhill migration of some males, we would expect those males to be bigger, older, and competitively dominant over resident males, and these individuals would be expected to sire more young. Conversely, if the advantage of remaining at high elevations is having first access to females arriving at swarming sites, then resident males should sire more young. In a comparative context, we would expect to see either a higher or lower incidence of downhill migration in species with less promiscuous mating systems under mate competition hypotheses with the direction of this prediction depending on whether mating occurs prior to uphill migration or occurs exclusively at high-elevation sites.

\section{(3) Why do tropical bats migrate altitudinally?}

Early studies of altitudinal migration in tropical birds noted the predominance of frugivorous and nectarivorous species among those making altitudinal migrations (Hilty, 1997; Skutch, 1969; Stiles, 1988). This observation led to many tests of hypotheses relying on seasonal and spatial availability of food (e.g. Loiselle \& Blake, 1991). The same hypothesis has been proposed for tropical frugivorous and nectarivorous bats (Cockrum, 1991; Fleming \& Eby, 2003; Fraser et al., 2010; Valiente-Banuet et al., 1996, 1997). Food availability can potentially explain both up- and downhill movements in tropical and sub-tropical bat species that forage year-round. For food to explain bat migration patterns, either the availability of the food resource consumed by the species must vary spatially and seasonally, or the bats' dietary requirements must change seasonally with the elevational distribution of those resources differing from one another.

In Costa Rica, Timm \& LaVal (2000) noted that the seasonal fluctuations of montane bat populations coincided with seasonal changes in abundance of fruit at their study site. Similarly 
the seasonal abundance of Sturnira lilium and Sturnira erythromos in the Argentinian Andes coincided with the fruiting of Piper and Solanum species, fruits common in the diets of these bats (Giannini, 1999). However, thus far, it is not clear if lower elevations (in Costa Rica) or higher elevations (in Argentina) have higher fruit production rates relative to the elevations and the times of year that these bats depart, a key prediction of this hypothesis. If food availability drives altitudinal migration, bats should always move to elevations with higher relative food abundance.

The availability of floral nectar has been hypothesized to shape the migration patterns of Leptonycteris yerbabuenae. If food availability drives these migrations, we predict that populations would remain sedentary in areas where food remained available year-round. Furthermore, variation in flowering phenology at different elevations may lead to exclusively altitudinal migrations (with no latitudinal component). Evidence supports both predictions. In Baja California, the flowering of columnar cacti and Agave spp. is relatively aseasonal, with many species flowering throughout the winter (Fleming, Nuñez \& Sternberg, 1993) and $L$. yerbabuenae are non-migratory in this region (Fleming et al., 1993; Woloszyn \& Woloszyn, 1982). Furthermore, several studies have suggested that L. yerbabuenae in southern Mexico make altitudinal rather than latitudinal migrations (Herrera-Montalvo, 1997; Rojas-Martínez et al., 1999; Valiente-Banuet et al., 1996, 1997). The hypothesized function of these movements is to track floral abundance as flowering phenology moves up mountain slopes. This explanation is the same as that proposed to explain the altitudinal component of the migration patterns of $L$. yerbabuenae populations reaching the SW USA (Cockrum, 1991).

Although tracking food resources is an intuitive explanation for altitudinal migration, we caution researchers to consider alternative hypotheses. For decades, ornithologists tested 
predictions of food-based hypotheses in isolation. Yet the manakin system reveals how interactions between climate and dietary needs likely explain these migrations, not only in this species but apparently in whole communities of tropical altitudinal migrants (Boyle, 2011). Recent work from Hawai'i suggests that such interacting effects of weather and food may shape bat altitudinal migrations of Lasiurus cinereus semotus (an insectivore). One hypothesis to explain upslope migration during the non-breeding season is that storms limit foraging opportunities for aerial prey. Furthermore, during the non-breeding season males appear to migrate upslope in advance of females, possibly as the (larger) females out-compete the (smaller) males (Menard, 2001). The idea of upslope migration in response to storm-related reduced prey availability is consistent with the fact that on the leeward (drier) side of the island, fewer individuals migrate. Some evidence suggests that upslope migration may also function to take advantage of seasonal moth irruptions at high-elevation sites (Todd et al., 2009). Even in the absence of irruptive prey, cooler temperatures at high elevations could reduce energy expenditures through use of torpor. Taken together, this relatively simple migration system may combine elements of three hypotheses: limited foraging opportunities (winter storms hinder foraging in lowlands), food abundance (upslope migrations track moth irruptions), and energetics/torpor use at high elevation. Investigations in Hawai' i are ongoing (F. Bonaccorso, personal communication) and we anticipate many novel insights from this migration system.

The patterns of altitudinal migration in the Galapagos Islands are similar to those observed in Hawai $i$ in several respects. Upslope migration during the breeding season could enable bats to avoid high temperatures and intense rainstorms in the lowlands. It is unclear whether rainstorms might influence migratory movements by limiting the ability of bats to forage for aerial insect prey, or act via more direct physiological effects of high temperatures and heavy 
rain. The pattern of altitudinal sexual segregation in the Galapagos (females low, males high during non-breeding season) is similar to that observed in Hawai $i$ with the important difference of breeding elevation. In Hawai' i, breeding occurs in the lowlands, and males migrate upslope in advance of females in the post-breeding period (Menard, 2001). By contrast, breeding apparently occurs at higher elevations in the Galapagos, and females migrate downslope during the nonbreeding season (McCracken et al., 1997). If the Galapagos females migrate upslope to breed, no clear explanation exists for their return downhill.

\section{TAKING BAT ALTITUDINAL MIGRATION STUDIES TO NEW HEIGHTS}

This review documents considerable evidence supporting the existence of altitudinal migration of bats. Altitudinal migration putatively occurs in populations living in mountainous regions worldwide (Table 1) and is clearly an important component of the life cycle of many bat species. Also clear, however, is that we have only minimal information on the basic movement patterns of many species, and virtually no hypothesis-driven research investigating the causes and consequences of these migrations. Altitudinal bat migrations appear to be most common in Vespertilionidae and Phyllostomidae. With the exception of one anecdotal report from Nepal, tropical reports are restricted to the New World (likely reflecting variation in research intensity rather than biological patterns given the high proportion of Himalayan bird species that migrate altitudinally). Advancement in this area of research will require creative approaches to both documenting the basic patterns in systems where movements are poorly described, and devising studies that effectively distinguish among the proposed hypotheses that could explain the migrations of better-studied species. Among the species listed in Table 1, wide-ranging species 
with populations found in non-mountainous regions, where altitudinal migration is not possible, provide a valuable opportunity for intra-specific comparative studies.

To promote further study, we outline (in ascending order of discriminatory power) methods to document patterns of altitudinal migration (Table 2). These methods can be used to test the predictions outlined in the previous sections to discriminate between the many hypotheses capable of explaining patterns of altitudinal bat migration. Some of the temperate systems (i.e. Myotis daubentonii in Europe, Eptesicus fuscus or Myotis lucifugus in N. America) are ripe for the kind of in-depth investigations recently appearing in the avian literature. In the tropics, most studies must necessarily begin by determining the temporal and spatial patterns of movement before the causes of those movements can be addressed. The predictions included herein are by no means exhaustive, but it is our hope that by identifying connections between observable patterns and underlying drivers, we will encourage more researchers to delve into this wide-open area of study.

Recent technological advances provide several new tools applicable to the study of bat altitudinal migration. Integrating methods such as radio-telemetry and passive integrated transponders (e.g. Neubaum et al., 2006) has enabled detailed and spatially extensive data to be collected on individual animals. Stable isotope analysis is another promising technique that has been used in tropical altitudinal bird migration (Boyle et al., 2011; Hobson et al., 2003), although application of stable isotope methods in bat studies has thus far proven problematic (Fraser et al., 2010). Both isotopes and telemetry allow researchers to document the movement patterns of individuals, information that is critical to providing unequivocal evidence of migration itself, as well as elucidating the drivers of those migrations. Furthermore, many hypotheses lead to predictions involving variation in physiological factors (e.g. body mass, 
heterothermy, fuelling rate, energy balance). Therefore, integration of physiological methods into ecological field studies can also greatly expand our ability to distinguish among hypotheses explaining variation in individual movement patterns (e.g. Boyle et al., 2010). Researchers can assess simple body condition indices (Russo, 2002; Senior et al., 2005), or preferably, use respirometry (Cryan \& Wolf, 2003), skin-temperature sensitive telemetry (Willis et al., 2006), heart rate telemetry (Dechmann et al., 2011), doubly-labelled water (Butler et al., 2004), and quantitative magnetic resonance (McGuire \& Guglielmo, 2010) to test physiological predictions of hypotheses proposed (see above) to explain altitudinal migrations of bats.

Altitudinal bat migration is an important part of the ecology of many species. The IUCN has recognized the need for further investigation of altitudinal bat migration (Hutson et al., 2001). As ongoing climate change pushes montane plant and animal communities upslope, population fragmentation and ultimately the extinction of species dependent upon the highestelevation habitats is inevitable (Colwell et al., 2008). Not only will year-round residents of high elevations experience the adverse effects of upward-shifting climatic optima and food plant distributions, but altitudinal migrants will likewise find that habitats they depend on for part of their annual cycle have disappeared. When we overlay these climate-related stressors on other threats to bat populations such as habitat destruction and other factors associated with increasing human populations (Hutson et al., 2001), emerging infectious diseases (e.g. white-nose syndrome; Cryan et al., 2010) and other anthropogenic threats (e.g. wind-farm mortality; Cryan \& Barclay, 2009), a bleak picture emerges of future bat communities, and indeed, the integrity of many terrestrial ecosystems. Without substantial improvements in our understanding of the patterns and causes of bat migrations, even if those migrations are over short distances along elevational gradients, conservation strategies for many species will likely prove inadequate. 


\section{CONCLUSIONS}

(1) Although rarely documented in any detail, altitudinal migration appears to be a common phenomenon in bats around the world. We compiled evidence indicative or consistent with altitudinal migration in 61 species of bats from five families in 21 countries on four continents. (2) The patterns (and proposed drivers) of altitudinal migration varied biogeographically. In temperate regions, altitudinal migration is sex-biased with females (and perhaps some males) spending the breeding season at low elevations while most (or all) males remain at high elevations. In the tropics, there is no apparent sex bias in most studies.

(3) In some temperate migration systems (e.g. certain populations of Myotis daubentonii in Europe, or Eptesicus fuscus in North America), the patterns associated with altitudinal migration have been sufficiently documented that it may now be possible to begin testing hypotheses to explain these movements. In the tropics, basic movement patterns have yet to be described in sufficient detail. For both regions, we identified hypotheses proposed to explain migratory movements and we provide testable predictions to discriminate among the various hypotheses. (4) Comparing bat and bird altitudinal migration systems promises to yield valuable insight into the evolution of complex migration patterns. In some cases, ecological parallels lead to striking similarities (e.g. partial altitudinal migration in bat and bird species that forage in riparian areas) while in other cases, opposite migration patterns are observed despite similar morphology (e.g. partial migration biased towards large-bodied sex in bats and the smaller sex/individuals in birds). Key differences between bats and birds (especially reproductive physiology and thermoregulatory strategies) likely drive many of these patterns. 
(5) Effective conservation strategies must include all parts of the annual cycle of migrants. Thus, documenting and understanding altitudinal migration in bats is critical particularly as global climate change leads to shifts in the climatic profile of alpine regions worldwide.

\section{ACKNOWLEDGMENTS}

Both authors gratefully acknowledge financial support from the Natural Sciences and Engineering Research Council of Canada (Canada Graduate Scholarship to L.P.M. and postdoctoral fellowship to W.A.B.) during the preparation of this manuscript. We thank Chris Guglielmo for advice and support throughout the writing of the manuscript, and Brock Fenton, Paul Cryan, and three anonymous reviewers for critical comments that improved the clarity and quality of this work. Thanks to Silke Nebel and Ying-Yi Ho for assistance with translations.

\section{REFERENCES}

Allen, G. M. (1919). Bats from Mount Whitney, California. Journal of Mammalogy 1, 1-5.

Alves, M. A. S. (2007). Bird migration systems in Brazilian terrestrial habitats: examples, gaps of knowledge, and directions for future studies. Revista Brasileira De Ornitologia 15, 231238.

BAKER, M. D. \& LACKI, M. J. (2004). Forest bat communities in the East Cascade range, Washington. Northwest Science 78, 234-241.

BARCLAY, R. M. R. (1991). Population structure of temperate zone insectivorous bats in relation to foraging behavior and energy demand. Journal of Animal Ecology 60, 165-178.

BARClAy, R. M. R. \& HARder, L. D. (2003). Life histories of bats: life in the slow lane. In Bat Ecology (ed. T. H. Kunz and M. B. Fenton), pp. 209-253. University of Chicago Press, 


\section{Chicago.}

BARry, R. G. (2008). Mountain Weather and Climate, third edition. Cambridge University Press, Cambridge; New York.

BeEBE, W. (1947). Avian migration at Rancho Grande in north-central Venezuela. Zoologica 32, $153-168$.

Belthoff, J. R. \& Gauthreaux, S. A. (1991). Partial migration and differential winter distribution of House Finches in the eastern United States. Condor 93, 374-382.

BENCKE, G. A. \& KINDEL, A. (1999). Bird counts along an altitudinal gradient of Atlantic forest in northeastern Rio Grande do Sul, Brazil. Ararajuba 7, 91-107.

Bisson, I. A., SAFI, K. \& Holland, R. A. (2009). Evidence for repeated independent evolution of migration in the largest family of bats. Plos One 4.

Bonaccorso, F. J., Gorresen, M. P., Pinzari, C. A. \& Todd, C. W. (2009). Why do Hawaiian hoary bats migrate to high elevations in winter? Bat Research News 50, 93-94.

Bonaccorso, F. J., Gorresen, M. P., Todd, C. W., Cornett, C. \& Pinzari, C. A. (2008). Seasonal variation in habitat occupancy by Hawaiian hoary bats. Bat Research News 49, 101102.

BOYLE, W. A. (2008a). Can variation in risk of nest predation explain altitudinal migration in tropical birds? Oecologia 155, 397-403

BOYLE, W. A. (2008b). Partial migration in birds: tests of three hypotheses in a tropical lekking frugivore. Journal of Animal Ecology 77, 1122-1128.

Boyle, W. A. (2010). Does food abundance explain altitudinal migration in a tropical frugivorous bird? Canadian Journal of Zoology 88, 204-213.

BOYLE, W. A. (2011). Short-distance partial migration of Neotropical birds: a community-level 
test of the foraging limitation hypothesis. Oikos 120, 1803-1816.

Boyle, W. A., Guglielmo, C. G., Hobson, K. A. \& Norris, D. R. (2011). Lekking birds in a tropical forest forego sex for migration. Biology Letters 7, 661-663.

Boyle, W. A., Norris, D. R. \& Guglielmo, C. G. (2010). Storms drive altitudinal migration in a tropical bird. Proceedings of the Royal Society B-Biological Sciences 277, 2511-2519.

Boyle, W. A., Winkler, D. W. \& Guglielmo, C. G. (2012). Rapid loss of fat but not lean mass prior to chick provisioning supports the flight efficiency hypothesis in Tree Swallows. Functional Ecology 26, 895-903.

Burgess, N. D. \& Mlingwa, C. O. F. (2000). Evidence for altitudinal migration of forest birds between montane Eastern Arc and lowland forests in East Africa. Ostrich 71, 184-190.

Butler, P. J., Green, J. A., Boyd, I. L. \& Speakman, J. R. (2004). Measuring metabolic rate in the field: the pros and cons of the doubly labelled water and heart rate methods. Functional Ecology 18, 168-183.

CAlder, W. A. (1974). Consequences of body size for avian energetics. In Avian Energetics (ed. R. A. Paynter), pp. 86-144. Nuttall Ornithological Club Publication 15, Cambridge, MA. Chaves-CAMPos, J. (2004). Elevational movements of large frugivorous birds and temporal variation in abundance of fruits along an elevational gradient. Ornitología Neotropical 15, $433-445$.

Cheng, H.-C. (2009). The night elves: the amazing survival abilities of bats. Scientific American (Traditional Chinese edition) 83, 2-7.

Cheng, H.-C., FAnG, Y.-P. \& CHOU, C.-H. (2010). A photographic guide to the bats of Taiwan. Endemic Species Research Institute, Council of Agriculture, Taiwan.

Cheng, H.-C., Tsai, B.-L., Yang, S.-D. \& Chang Chien, L.-W. (2009). From a hibernating 
colony of Murina bicolor to the wintering strategy of bats in Taiwan. Nature Conservation Quarterly 67, 75-80.

COCKRUM, E. L. (1991). Seasonal distribution of northwestern populations of the long-nosed bats Leptonycteris sanborni Family Phyllostomidae. Anales del Instituto de Biología, Universidad Nacional Autónoma de México, Serie Zoologia 62, 181-202.

Cockrum, E. L. \& Ordway, E. (1959). Bats of the Chiricahua Mountains, Cochise County, Arizona. American Museum Novitates 1938, 1-35.

Colwell, R. K., Brehm, G., CARdelus, C. L., Gilman, A. C. \& Longino, J. T. (2008). Global warming, elevational range shifts, and lowland biotic attrition in the wet tropics. Science 322, 258-261.

Constantine, D. G. (1967). Activity patterns of the Mexican free-tailed bat. University of New Mexico Publications in Biology 7, 1-79.

Cox, G. W. (1968). The role of competition in the evolution of migration. Evolution 22, 180-192.

CRichton, E. G. (2000). Sperm storage and fertilization. In Reproductive biology of bats (ed. E. G. Crichton and P. H. Krutzsch), pp. 295-320. Academic Press, San Diego, CA, USA.

Cristol, D. A., BAKER, M. C. \& CoRBOnE, C. (1999). Differential migration revisited: latitudinal segregation by age and sex class. Current Ornithology 15, 33-88.

CRYAN, P. M. (2003). Seasonal distribution of migratory tree bats (Lasiurus and Lasionycteris) in North America. Journal of Mammalogy 84, 579-593.

CRYAN, P. M. \& BARCLAY, R. M. R. (2009). Causes of bat fatalities at wind turbines: hypotheses and predictions. Journal of Mammalogy 90, 1330-1340.

Cryan, P. M., Bogan, M. A. \& Altenbach, J. S. (2000). Effect of elevation on distribution of female bats in the Black Hills, South Dakota. Journal of Mammalogy 81, 719-725. 
Cryan, P. M., Meteyer, C. U., Boyles, J. G. \& Blehert, D. S. (2010). Wing pathology of white-nose syndrome in bats suggests life-threatening disruption of physiology. BMC Biology $\mathbf{8}, 135$.

Cryan, P. M. \& Wolf, B. O. (2003). Sex differences in the thermoregulation and evaporative water loss of a heterothermic bat, Lasiurus cinereus, during its spring migration. Journal of Experimental Biology 206, 3381-3390.

Dalquest, W. W. (1943). Distribution of the Hoary Bat along the Pacific coast. The Murrelet 24, 21-24.

DAVIS, W. H. (1959). Taxonomy of the eastern pipistrel. Journal of Mammalogy 40, 521-531.

Dechmann, D. K. N., Ehret, S., Gaub, A., Kranstauber, B. \& Wikelski, M. (2011). Low metabolism in a tropical bat from lowland Panama measured using heart rate telemetry: an unexpected life in the slow lane. Journal of Experimental Biology 214, 3605-3612.

Dixon, K. L. \& GiLberT, J. D. (1964). Altitudinal migration in the Mountain Chickadee. Condor 66, 61-64.

EASTERLA, D. A. (1973). Ecology of the 18 species of Chiroptera at Big Bend National Park, Texas. The Northwest Missouri State University Studies 34, 1-165.

Encarnação, J. A., Kierdorf, U., Holweg, D., Jasnoch, U. \& Wolters, V. (2005). Sexrelated differences in roost-site selection by Daubenton's bats Myotis daubentonii during the nursery period. Mammal Review 35, 285-294.

Esbérard, C. E. L., De Lima, I. P., Nobre, P. H., Althoff, S. L., Jordẽo-Nogueira, T., Dias, D., Carvalho, F., Fabián, M. E., Sekiama, M. L. \& Sobrinho, A. S. (2011). Evidence of vertical migration in the lpanema bat Pygoderma bilabiatum (Chiroptera: Phyllostomidae: Stenodermatinae). Zoologia 28, 717-724. 
FENTON, M. B. (1969). Summer activity of Myotis lucifugus (Chiroptera - Vespertilionidae) at hibernacula in Ontario and Quebec. Canadian Journal of Zoology 47, 597-602.

Fenton, M. B., Dejong, C. G. V., Bell, G. P., Campbell, D. B. \& Laplante, M. (1980).

Distribution, parturition dates, and feeding of bats in south-central British Columbia.

Canadian Field-Naturalist 94, 416-420.

Ferrari, S., Albrielu, C., ImBerti, S. \& Lishman, C. (2008). The up-to-date knowledge of the Magellanic Plover (Pluvianellus socialis), an endemic shorebird of Southern Patagonia:

putting together the pieces of the puzzle. Ornitologia Neotropical 19, 433-443.

FINDLEY, J. S. \& JONES, C. (1964). Seasonal distribution of the hoary bat. Journal of Mammalogy 45, 461-470.

Fleming, T. H. \& EBy, P. (2003). Ecology of bat migration. In Bat Ecology (ed. T. H. Kunz and M. B. Fenton), pp. 156-208. University of Chicago Press, Chicago.

Fleming, T. H., NuÑEZ, R. A. \& STERnBERG, L. S. (1993). Seasonal changes in the diets of migrant and non-migrant nectarivorous bats as revealed by carbon stable isotope analysis. Oecologia 94, 72-75.

FraSer, K. C., KySER, T. K. \& RATCLIFFE, L. M. (2008). Detecting altitudinal migration events in Neotropical birds using stable isotopes. Biotropica 40, 269-272.

Fraser, K. C., MCKinNon, E. A. \& DiAmond, A. W. (2010). Migration, diet, or molt? Interpreting stable-Hydrogen isotope values in Neotropical bats. Biotropica 42, 512-517.

FreTwell, S. D. (1972). Populations in a Seasonal Environment. Princeton University Press, Princeton, NJ.

FRETWELL, S. D. (1980). Evolution of migration in relation to factors regulating bird numbers. In Migrant Birds in the Neotropics (ed. A. Keast and E. S. Morton), pp. 517-527. Smithsonian 
Institution Press, Washington, DC.

GIANNINI, N. P. (1999). Selection of diet and elevation by sympatric species of Sturnira in an Andean rainforest. Journal of Mammalogy 80, 1186-1195.

Gillis, E. A., Green, D. J., Middleton, H. A. \& Morrissey, C. A. (2008). Life history correlates of alternative migratory strategies in American Dippers. Ecology 89, 1687-1695.

GREEN, K. (2006). Effect of variation in snowpack on timing of bird migration in the Snowy Mountains of south-eastern Australia. Emu 106, 187-192.

GREENBERG, R. (1980). Demographic aspects of long-distance migration. In Migrant Birds in the Neotropics (ed. A. Keast and E. S. Morton), pp. 493-504. Smithsonian Institution Press, Washington, DC.

GRIFFIN, D. R. (1970). Migrations and homing of bats. In Biology of Bats, vol. I (ed. W. A. Wimsatt), pp. 233-264. Academic Press Inc., New York, NY.

Grindal, S. D., COllard, T. S. \& BrighaM, R. M. (1992). The influence of precipitation on reproduction by Myotis bats in British Columbia. American Midland Naturalist 128, 339-344.

Grindal, S. D., Morissette, J. L. \& Brigham, R. M. (1999). Concentration of bat activity in riparian habitats over an elevational gradient. Canadian Journal of Zoology 77, 972-977.

Grinevitch, L., Holroyd, S. L. \& BArclay, R. M. R. (1995). Sex differences in the use of daily torpor and foraging time by Big Brown Bats (Eptesicus fuscus) during the reproductive season. Journal of Zoology 235, 301-309.

GRINNELL, H. W. (1918). A synopsis of the bats of California. University of California Publications in Zoology 17, 223-404.

Grinnell, J. \& MiLler, A. H. (1944). The distribution of the birds of California. Cooper Ornithological Society, Berkeley, CA. 
Gross, M. R., Coleman, R. M. \& McDowall, R. M. (1988). Aquatic productivity and the evolution of diadromous fish migration. Science 239, 1291-1293.

HABer, W. A. \& Stevenson, R. D. (2004). Diversity, migration, and conservation of butterflies in northern Costa Rica. In Biodiversity Conservation in Costa Rica: Learning the Lessons in a Seasonal Dry Forest (ed. G. W. Frankie, A. Mata and S. B. Vinson), pp. 99-114. University of California Press, Berkeley, CA.

Hebblewhite, M. \& Merrill, E. H. (2009). Trade-offs between predation risk and forage differ between migrant strategies in a migratory ungulate. Ecology $\mathbf{9 0}, 3445-3454$.

HERRERA-Montalvo, L. G. (1997). Evidence of altitudinal movements of Leptonycterys curasoae (Chiroptera: Phyllostomidae) in Central Mexico. Revista Mexicana de Mastozoologia 2, 116-118.

HiLTY, S. L. (1997). Seasonal distribution of birds at a cloud-forest locality, the Anchicayá Valley, in western Colombia. Ornithological Monographs 48, 321-343.

Hobson, K. A., WassenaAr, L. I., Milá, B., Lovette, I., Dingle, C. \& Smith, T. B. (2003). Stable isotopes as indicators of altitudinal distributions and movements in an Ecuadorean hummingbird community. Oecologia 136, 302-308.

HOFFMEISTER, D. F. (1970). The seasonal distribution of bats in Arizona: a case for improving mammalian range maps. Southwestern Naturalist 15, 11-22.

HolZHAider, J. \& ZAHN, A. (2001). Bats in the Bavarian Alps: species composition and utilization of higher altitudes in summer. Mammalian Biology 66, 144-154.

Howell, A. B. (1920). Some Californian experiences with bat roosts. Journal of Mammalogy 1, $169-177$.

Hunt, J. H., Brodie, R. J., Carithers, T. P., Goldstein, P. Z. \& Janzen, D. H. (1999). Dry 
season migration by Costa Rican lowland paper wasps to high elevation cold dormancy sites. Biotropica 31, 192-196.

Hutson, A. M. (2002). A feasibility study on additional bats agreements under CMS.

Convention on the Conservation of Migratory Species of Wild Animals, United Nations Environment Program. UNEP/ScC11/Doc.7.

Hutson, A. M. (2004). Update to: A feasibility study on additional bats agreements under CMS. Convention on the Conservation of Migratory Species of Wild Animals, United Nations Environment Program. Update of UNEP/ScC11/Doc.7.

Hutson, A. M., Mickleburgh, S. P. \& Racey, P. A. (2001). Microchiropteran bats: global status survey and conservation action plan, pp. 258. IUCN/SSC Chiroptera Specialist Group. IUCN, Gland, Switzerland and Cambridge, UK.

Hutterer, R., Ivanova, T., Meyer-Cords, C. \& Rodrigues, L. (2005). Bat migrations in Europe: a review of banding data and literature, pp. 162. Federal Agency for Nature Conservation in Germany, Bonn, Germany.

JABERG, C. \& GuISAN, A. (2001). Modelling the distribution of bats in relation to landscape structure in a temperate mountain environment. Journal of Applied Ecology 38, 1169-1181.

Johnson, D. N. \& MACLEAN, G. L. (1994). Altitudinal migration in Natal. Ostrich 65, 86-94.

KAŇUCH, P. \& KRIŠTín, A. (2006). Altitudinal distribution of bats in the Pol'ana Mts area (Central Slovakia). Biologia, Bratislava 61, 605-610.

KetTerson, E. D. \& NOLAn, V., JR. (1976). Geographic variation and its climatic correlates in sex-ratio of eastern wintering Dark-eyed Juncos (Junco hyemalis hyemalis). Ecology 57, 679693.

KLUG, B. J. \& BARCLAY, R. M. R. (In press). Thermoregulation during reproduction in the 
solitary, foliage-roosting hoary bat (Lasiurus cinereus). Journal of Mammalogy.

Kunz, T. H. (1982). Lasionycteris noctivagans. Mammalian Species 172, 1-5.

KuRta, A., Bell, G. P., NAGY, K. A. \& KunZ, T. H. (1989). Energetics of pregnancy and lactation in free-ranging Little Brown Bats (Myotis lucifugus). Physiological Zoology 62, 804818.

LANK, D. B., ButLeR, R. W., IRELAND, J. \& YDENBERG, R. C. (2003). Effects of predation danger on migration strategies of sandpipers. Oikos 103, 303-319.

LeUZinger, Y. \& BRossARD, C. (1994). Répartition de M. daubentonii en function du sexe et de la période de l'année dans le Jura bernois. Résultats preliminaries. Mitteilungen der Naturforschenden Gesellschaft Schaffhausen 39, 135-143.

LEVEY, D. J. \& STILES, F. G. (1992). Evolutionary precursors of long-distance migration: resource availability and movement patterns in Neotropical landbirds. American Naturalist $140,447-476$.

LEWIS, S. E. (1993). Effect of climatic variation on reproduction by pallid bats (Antrozous pallidus). Canadian Journal of Zoology 71, 1429-1433.

Loiselle, B. A. \& BlAKE, J. G. (1991). Temporal variation in birds and fruits along an elevational gradient in Costa Rica. Ecology 72, 180-193.

Loucks, C. J., Lu, Z., Dinerstein, E., WANG, D. J., Fu, D. L. \& WANG, H. (2003). The giant pandas of the Qinling Mountains, China: A case study in designing conservation landscapes for elevational migrants. Conservation Biology 17, 558-565.

Mackas, R. H., Green, D. J., Whitehorne, I. B. J., Fairhurst, E. N., Middleton, H. A. \& MorRissey, C. A. (2010). Altitudinal migration in American Dippers (Cinclus mexicanus): Do migrants produce higher quality offspring? Canadian Journal of Zoology 88, 369-377. 
MCCAIN, C. M. (2007). Could temperature and water availability drive elevational species richness patterns? A global case study for bats. Global Ecology and Biogeography 16, 1-13.

McCarthy, T. J., Maston, J. O., Rodríguez-Herrera, B. \& Handley JR., C. O. (2005). Distribution, morphometrics, and identification of the Talamancan epaulette bat (Sturnira mordax) of Costa Rica and Panama. In Contribuciones Mastozoológicas en Homenaje a Bernardo Villa (ed. V. Sánchez-Cordero and R. A. Medellín), pp. 349-362. Universidad Nacional Autónoma de México, Mexico.

McCracken, G. F., Hayes, J. P., Cevallos, J., Guffey, S. Z. \& Romero, F. C. (1997). Observations on the distribution, ecology, and behaviour of bats on the Galapagos Islands. Journal of Zoology (London) 243, 757-770.

McGuiRe, L. P. \& Guglielmo, C. G. (2009). What can birds tell us about the migration physiology of bats? Journal of Mammalogy 90, 1290-1297.

MCGuire, L. P. \& Guglielmo, C. G. (2010). Quantitative magnetic resonance: a rapid, noninvasive body composition analysis technique for live and salvaged bats. Journal of Mammalogy 91, 1375-1380.

McGuire, L. P., Guglielmo, C. G., Mackenzie, S. A. \& TAYlor, P. D. (2011). Migratory stopover in the long-distance migrant silver-haired bat, Lasionycteris noctivagans. Journal of Animal Ecology 81, 377-385.

MENARD, T. (2001). Activity patterns of the Hawaiian hoary bat (Lasiurus cenereus semotus) in relation to reproductive time periods, MS thesis, University of Hawai'i.

Middleton, H. A. \& GreEn, D. J. (2008). Correlates of postfledging survival, the timing of dispersal, and local recruitment in American Dippers. Canadian Journal of Zoology 86, 875881. 
Middleton, H. A., Morrissey, C. A. \& Green, D. J. (2006). Breeding territory fidelity in a partial migrant, the American dipper Cinclus mexicanus. Journal of Avian Biology 37, 169178.

Morbey, Y. E. \& YDEnBERG, R. C. (2001). Protandrous arrival timing to breeding areas: a review. Ecology Letters 4, 663-673.

MORRISSEY, C. A. (2004). Effect of altitudinal migration within a watershed on the reproductive success of American Dippers. Canadian Journal of Zoology 82, 800-807.

Morrissey, C. A., Bendell-Young, L. I. \& Elliott, J. E. (2004). Seasonal trends in population density, distribution, and movement of American Dippers within a watershed of southwestern British Columbia, Canada. Condor 106, 815-825.

MYSTERUD, A. (1999). Seasonal migration pattern and home range of roe deer (Capreolus capreolus) in an altitudinal gradient in southern Norway. Journal of Zoology 247, 479-486.

Mysterud, A., Langvatn, R., Yoccoz, N. G. \& Stenseth, N. C. (2001). Plant phenology, migration and geographical variation in body weight of a large herbivore: the effect of a variable topography. Journal of Animal Ecology 70, 915-923.

Neubaum, D. J., O'SheA, T. J. \& Wilson, K. R. (2006). Autumn migration and selection of rock crevices as hibernacula by big brown bats in Colorado. Journal of Mammalogy 87, 470-479.

O'Shea, T. J., Cryan, P. M., Snider, E. A., Valdez, E. W., Ellison, L. E. \& Neubaum, D. J. (2011a). Bats of Mesa Verde National Park, Colorado: composition, reproduction, and roosting habits. Monographs of the Western North American Naturalist 5, 1-19.

O'Shea, T. J., Neubaum, D. J., Neubaum, M. A., Cryan, P. M., Ellison, L. E., Stanley, T. R., RupPRECht, C. E., PAPE, W. J. \& Bowen, R. A. (2011b). Bat ecology and public health surveillance for rabies in an urbanizing region of Colorado. Urban Ecosystems 14, 665-697. 
ORNELAS, J. F. \& ARIZMENDI, M. D. C. (1995). Altitudinal migration: implications for the conservation of the Neotropical migrant avifauna of western Mexico. In Conservation of Neotropical Migratory Birds in Mexico (ed. M. H. Wilson and A. Sader), pp. 98-109. Maine Agricultural and Forest Experiment Station. Miscellaneous Publications 727.

Pierson, E. D., RAIney, W. E. \& Corben, C. J. (2001). Seasonal patterns of bat distribution along an altitudinal gradient in the Sierra Nevada. California Department of Transportation, California State University at Sacramento Foundation, The Yosemite Association, and The Yosemite Fund.

PIKSA, K. (2008). Swarming of Myotis mystacinus and other bat species at high elevation in the Tatra Mountains, southern Poland. Acta Chiropterologica 10, 69-79.

Piksa, K., Bogdanowicz, W. \& TerebA, A. (2011). Swarming of bats at different elevations in the Carpathian Mountains. Acta Chiropterologica 13, 113-122.

Pinzari, C. A., Bonaccorso, F. J. \& Gorresen, M. P. (2009). Timing of Hawaiian hoary bat (Lasiurus cinereus semotus) echolocation activity by season on windward Hawaii Island. Bat Research News 50, 134.

Popa-Lisseanu, A. G. \& Voigt, C. C. (2009). Bats on the move. Journal of Mammalogy 90, 1283-1289.

POWELl, G. V. N. \& BJORK, R. D. (1995). Implications of intratropical migration on reserve design: a case study using Pharomachrus mocinno. Conservation Biology 9, 354-362.

Powell, G. V. N. \& BJORK, R. D. (2004). Habitat linkages and the conservation of tropical biodiversity as indicated by seasonal migrations of Three-wattled Bellbirds. Conservation Biology 18, 500-509.

Presnall, C. C. (1935). Altitudinal migration in southern Utah. Condor 37, 37-38. 
RABENOLD, K. N. \& RABENOLD, P. P. (1985). Variation in altitudinal migration, winter segregation, and site-tenacity in two subspecies of Dark-eyed Juncos in the southern Appalachians. Auk 102, 805-819.

RACEY, P. A. (1973). Environmental factors affecting the length of gestation in heterothermic bats. Journal of Reproductive Fertility Supplement 19 175-189.

RACEY, P. A. \& SWIFT, S. M. (1981). Variations in gestation length in a colony of pipistrelle bats (Pipistrellus pipistrellus) from year to year. Journal of Reproductive Fertility 61, 123-129.

Ramos-Olmos, M. A. (1983). Seasonal movements of bird populations at a Neotropical study site in southern Veracruz, Mexico. Ph.D. thesis, University of Minnesota.

RiCE, C. G. (2008). Seasonal altitudinal movements of Mountain Goats. Journal of Wildlife Management 72, 1706-1716.

Rojas-Martínez, A., Valiente-Banuet, A., Arizmendi, M. D., Alcantara-Eguren, A. \& ARITA, H. T. (1999). Seasonal distribution of the long-nosed bat (Leptonycteris curasoae) in North America: does a generalized migration pattern really exist? Journal of Biogeography 26, $1065-1077$.

RosenZweig, M. L. \& ABRAMSKy, Z. (1997). Two gerbils of the Negev: A long-term investigation of optimal habitat selection and its consequences. Evolutionary Ecology 11, 733756.

Rosselli, L. (1994). The annual cycle of the White-ruffed Manakin, Corapipo leucorrhoa, a tropical frugivorous altitudinal migrant, and its food plants. Bird Conservation International 4, 143-160.

Russo, D. (2002). Elevation affects the distribution of the two sexes in Daubenton's bats Myotis daubentonii (Chiroptera : Vespertilionidae) from Italy. Mammalia 66, 543-551. 
SANBORn, C. C. \& CReSPO, J. A. (1957). El murcielago blanquizco (Lasiurus cinereus) y sus subespecies. Boletin del Museo Argentino de Ciencias Naturales "Bernardino Rivadavia" 4, $1-13$.

SÁNCHEZ-CORDERO, V. (2001). Elevation gradients of diversity for rodents and bats in Oaxaca, Mexico. Global Ecology and Biogeography 10, 63-76.

SANIGA, M. (1995). Seasonal distribution, altitudinal and horizontal migration of the Wallcreeper (Tichodroma muraria) in the Mala-Fatra-Mountains, Slovak-Carpathians. Folia Zoologica 44, 237-246.

SAWYER, H. \& KAUFFMAN, M. J. (2011). Stopover ecology of a migratory ungulate. Journal of Animal Ecology 80, 1078-1087.

SCHOWALTER, D. B. (1980). Swarming, reproduction, and early hibernation of Myotis lucifugus and Myotis volans in Alberta, Canada. Journal of Mammalogy 61, 350-354.

Senior, P., Butlin, R. K. \& Altringham, J. D. (2005). Sex and segregation in temperate bats. Proceedings of the Royal Society B-Biological Sciences 272, 2467-2473.

Shump, K. A. JR., \& SHUMP, A. U. (1982) Lasiurus cinereus. Mammalian Species 185, 1-5.

SICK, H. (1993). Ornitologia Brasileira. Editora Nova Fronteira, Rio de Janiero, Brazil.

SKUTCH, A. F. (1967). Life histories of Central American highland birds. Publication of the Nuttall Ornithological Club No. 7.

SKuTCH, A. F. (1969). Life Histories of Central American Birds III: families Cotingidae, Pipridae, Formicariidae, Furnariidae, Dendrocolaptidae, and Picidae. Pacific Coast Avifauna Number 35, Cooper Ornithological Society, Berkeley, California.

SLud, P. (1964). The birds of Costa Rica: distribution and ecology. Bulletin of the American Museum of Natural History 128, 1-430. 
SolóRzano, S., Castillo, S., VAlverde, T. \& Ávila, L. (2000). Quetzal abundance in relation to fruit availability in a cloud forest of southeastern Mexico. Biotropica 32, 523-532.

SpEAKMAN, J. R. \& RowLAND, A. (1999). Preparing for inactivity: how insectivorous bats deposit a fat store for hibernation. Proceedings of the Nutrition Society 58, 123-131.

Speakman, J. R. \& Thomas, D. M. (2003). Physiological ecology and energetics of bats. In Bat Biology (ed. T. H. Kunz and M. B. Fenton), pp. 430-492. University of Chicago Press, Chicago, IL.

StEFANESCU, C. (2001). The nature of migration in the red admiral butterfly Vanessa atalanta: evidence from the population ecology in its southern range. Ecological Entomology 26, 525536.

StILES, G. F. (1988). Altitudinal movements of birds on the Caribbean slope of Costa Rica: implications for conservation. In Tropical Rainforests: Diversity and Conservation (ed. F. Alameda and C. M. Pringle), pp. 243-258. California Academy of Sciences, San Francisco, CA.

Symes, C. T., Wirminghaust, J. O. \& Downs, C. T. (2002). Species richness and seasonality of forest avifauna in three South African Afromontane forests. Ostrich 73, 106-113.

SzewCZaK, J. M., SzewczaK, S. M., Morrison, M. L. \& Hall, L. S. (1998). Bats of the White and Inyo mountains of California-Nevada. Great Basin Naturalist 58, 66-75.

THOMAs, D. W. (1988). The distribution of bats in different ages of Douglas Fir forests. Journal of Wildlife Management 52, 619-626.

Thomas, D. W., Fenton, M. B. \& BARClay, R. M. R. (1979). Social behavior of the Little Brown Bat, Myotis lucifugus.1. Mating Behavior. Behavioral Ecology and Sociobiology 6, 129-136. 
TimM, R. M. \& LAVAL, R. K. (2000). Mammals. In Monteverde: Ecology and conservation of a tropical cloud forest (ed. N. M. Nadkarni and N. T. Wheelwright), pp. 223-244 and 553-560. Oxford University Press, New York.

Todd, C. W., Pinzari, C. A., Yuen, B., Bonaccorso, F. J. \& Gorresen, M. P. (2009). Prey abundance and seasonal movements of the Hawaiian hoary bat (Lasiurus cinereus semotus). Bat Research News 50, 148-149.

Valiente-Banuet, A., Arizmendi, M. D., Rojas-Martínez, A. \& Dominguez-Canseco, L. (1996). Ecological relationships between columnar cacti and nectar-feeding bats in Mexico. Journal of Tropical Ecology 12, 103-119.

Valiente-Banuet, A., Rojas-Martínez, A., Casas, A., Arizmendi, M. D. \& Davila, P. (1997). Pollination biology of two winter-blooming giant columnar cacti in the Tehuacan valley, central Mexico. Journal of Arid Environments 37, 331-341.

Vaughan, T. A. \& Krutzsch, P. H. (1954). Seasonal distribution of the Hoary Bat in southern California. Journal of Mammalogy 35, 431-432.

Weller, T. J., Cryan, P. M. \& O'SheA, T. J. (2009). Broadening the focus of bat conservation and research in the USA for the 21st century. Endangered Species Research 8, 129-145.

WiLKInSON, G. S. (1987). Altruism and co-operation in bats. In Recent Advances in the Study of Bats (ed. M. B. Fenton, P. A. Racey and J. M. V. Rayner), pp. 299-323. Cambridge University Press, Cambridge.

WiLliamS, D. F. \& FindLEY, J. S. (1979). Sexual size dimorphism in vespertilionid bats. American Midland Naturalist 102, 113-126.

WiLlis, C. K. R., BRIGHAM, R. M. \& GEISER, F. (2006). Deep, prolonged torpor by pregnant, free-ranging bats. Naturwissenschaften 93, 80-83. 
Willson, M. F. \& Kingery, H. E. (2011). American Dipper (Cinclus mexicanus). In Bird Birds of North America Online (ed. A. Poole). Cornell Lab of Ornithology, Ithaca, NY. WiLson, D. E. \& REEDER, D. M. (2005). Mammal species of the world: a taxonomic and geographic reference, pp. 2142. Johns Hopkins University Press, Baltimore, MD.

Woloszyn, D. \& Woloszyn, B. W. (1982). Los mamíferos de la Sierra de la Laguna, Baja California Sur. Consejo Nacional de Ciencia y Technología, Mexico City, Mexico. 
Table 1. Summary of literature reporting or discussing altitudinal bat migration, listed by family and species. For each species, we note the reference(s), geographic location of the study, and include a brief description of the data. The nature of these studies is extremely variable. Some provide direct empirical evidence of altitudinal migration, others do not explicitly invoke altitudinal migration but contain observations consistent with altitudinal migration, and some do not present any data or evidence, but contain speculation regarding possible altitudinal migrations.

\begin{tabular}{lll}
\hline Taxon $\quad$ Location & References & Nature of data \\
\hline VESPERTILIONIDAE & & \\
Corynorhinus townsendii & & Band recoveries \\
South Dakota, USA & Cryan et al. (2000) & Hibernating range at higher elevation than summer range \\
California \& Nevada, & Szewczak et al. (1998) & \\
USA & & Only male captures at high elevation \\
Eptesicus fuscus & & Radio-tracking, passive integrated transponder detections, \\
Colorado, USA & Neubaum et al. (2006) & altitudinal based sex bias \\
& & Female bias at low elevation in summer, male bias at high
\end{tabular}




\begin{tabular}{|c|c|c|c|}
\hline Taxon & Location & References & Nature of data \\
\hline & South Dakota, USA & Cryan et al. (2000) & Variation in sex bias along altitudinal transect \\
\hline & Texas, USA & Easterla (1973) & Altitudinal sex segregation \\
\hline & \multirow[t]{2}{*}{ Washington, USA } & Thomas (1988) & $\begin{array}{l}\text { Only males at higher elevation in one mountain range but not } \\
\text { others }\end{array}$ \\
\hline & & Baker \& Lacki (2004) & Male bias at high elevation \\
\hline & British Columbia, & Fenton et al. (1980) & Male bias at higher elevation \\
\hline & Canada & Grindal et al. (1999) & $\begin{array}{l}\text { Altitudinal sex segregation of several species combined, } \\
\text { species-specific patterns not presented }\end{array}$ \\
\hline \multicolumn{4}{|c|}{ Eptesicus nilssonii } \\
\hline & Germany & Holzhaider \& Zahn (2001) & $\begin{array}{l}\text { Male bias at higher elevations, maternity colonies only at lower } \\
\text { elevation }\end{array}$ \\
\hline \multicolumn{4}{|c|}{ Eptesicus serotinus } \\
\hline & Slovakia & Kaňuch \& Krištín (2006) & Altitudinal sex segregation \\
\hline \multicolumn{4}{|c|}{ Lasionycteris noctivagans } \\
\hline & South Dakota, USA & Cryan et al. (2000) & Variation in sex bias along altitudinal transect \\
\hline
\end{tabular}




\begin{tabular}{|c|c|c|c|}
\hline Taxon & Location & References & Nature of data \\
\hline \multicolumn{2}{|r|}{ Arizona, USA } & $\begin{array}{l}\text { Cockrum \& Ordway (1959) } \\
\text { Hoffmeister (1970) }\end{array}$ & $\begin{array}{l}\text { Seasonal presence at different elevations } \\
\text { Altitudinal migration suggested but no evidence }\end{array}$ \\
\hline & Colorado, USA & O’Shea et al. (2011b) & Male bias at high elevation in summer \\
\hline & $\begin{array}{l}\text { British Columbia, } \\
\text { Canada }\end{array}$ & Grindal et al. (1999) & $\begin{array}{l}\text { Altitudinal sex segregation for all species combined but did not } \\
\text { present species-specific patterns }\end{array}$ \\
\hline \multicolumn{4}{|c|}{ Lasiurus blossevilli } \\
\hline & California, USA & Grinnell (1918) & $\begin{array}{l}\text { As Nycteris borealis; seasonal capture records: in summer } \\
\text { females at low elevation, males at higher elevations. Explicitly } \\
\text { suggest altitudinal migration }\end{array}$ \\
\hline & $\begin{array}{l}\text { Galapagos Islands, } \\
\text { Ecuador }\end{array}$ & McCracken et al. (1997) & $\begin{array}{l}\text { Lasiurus blossevilli brachyotis; altitudinal sex segregation in } \\
\text { non-breeding season, limited seasonal acoustic monitoring }\end{array}$ \\
\hline \multicolumn{4}{|c|}{ Lasiurus cinereus } \\
\hline & South Dakota, USA & Cryan et al. (2000) & Variation in sex bias along altitudinal transect \\
\hline & $\begin{array}{l}\text { Galapagos Islands, } \\
\text { Ecuador }\end{array}$ & McCracken et al. (1997) & $\begin{array}{l}\text { Limited seasonal acoustic monitoring; cited by Hutson et al. } \\
\text { (2001) and Menard (2001) }\end{array}$ \\
\hline & Hawai`i, USA & Bonaccorso et al. (2009); Todd & Regular seasonal acoustic monitoring across altitudinal gradient \\
\hline
\end{tabular}




\begin{tabular}{|c|c|c|c|}
\hline Taxon & Location & References & Nature of data \\
\hline & & $\begin{array}{l}\text { et al. (2009); Pinzari et al. } \\
\text { (2009) } \\
\text { Menard (2001) }\end{array}$ & $\begin{array}{l}\text { Seasonal observations at multiple elevations, seasonal sex-bias } \\
\text { change in lowlands }\end{array}$ \\
\hline & California, USA & $\begin{array}{l}\text { Dalquest (1943); } \\
\text { Vaughan \& Krutzsch (1954) }\end{array}$ & $\begin{array}{l}\text { Capture and museum records indicate seasonal absence, } \\
\text { altitudinal sex segregation }\end{array}$ \\
\hline & Colorado, USA & O'Shea et al. (2011b) & Male bias at high elevation in summer \\
\hline & $\begin{array}{l}\text { Chile, Colombia, } \\
\text { Venezuela }\end{array}$ & Sanborn \& Crespo (1957) & $\begin{array}{l}\text { Seasonal capture records; Findley \& Jones (1964), McCracken } \\
\text { et al. (1997), Hutson et al. (2001) and Menard (2001) cite } \\
\text { speculation in Sanborn \& Crespo (1957) }\end{array}$ \\
\hline \multicolumn{4}{|c|}{ Murina bicolor } \\
\hline & Taiwan & Cheng et al. (2009) & $\begin{array}{l}\text { High-elevation hibernation, only found at low elevations in } \\
\text { summer }\end{array}$ \\
\hline \multicolumn{4}{|c|}{ Myotis brandti } \\
\hline & Germany & Holzhaider \& Zahn (2001) & Male bias at higher elevations \\
\hline
\end{tabular}




\begin{tabular}{|c|c|c|c|}
\hline Taxon & Location & References & Nature of data \\
\hline & British Columbia, & Fenton et al. (1980) & Male bias at higher elevation \\
\hline & Canada & Grindal et al. (1999) & $\begin{array}{l}\text { Altitudinal sex segregation for several species combined, } \\
\text { species-specific patterns not presented }\end{array}$ \\
\hline & Washington, USA & Thomas (1988) & $\begin{array}{l}\text { Only males at higher elevation in one mountain range but not } \\
\text { others }\end{array}$ \\
\hline & & Baker \& Lacki (2004) & Male bias at high elevation \\
\hline & Colorado, USA & O'Shea et al. (2011a) & Reproductive females rare at high elevation \\
\hline \multicolumn{4}{|c|}{ Myotis ciliolabrum } \\
\hline & South Dakota, USA & Cryan et al. (2000) & Variation in sex bias along altitudinal transect \\
\hline & Washington, USA & Thomas (1988) & $\begin{array}{l}\text { Only males at higher elevation in one mountain range but not } \\
\text { others }\end{array}$ \\
\hline & & Baker \& Lacki (2004) & Male bias at high elevation \\
\hline & Colorado, USA & O'Shea et al. (2011a) & Reproductive females rare at high elevation \\
\hline \multicolumn{4}{|c|}{ Myotis daubentonii } \\
\hline & Switzerland & Leuzinger \& Brossard (1994) & Seasonal altitudinal sexual segregation \\
\hline
\end{tabular}




\begin{tabular}{|c|c|c|c|}
\hline Taxon & Location & References & Nature of data \\
\hline & Italy & Russo (2002) & Seasonal altitudinal sexual segregation \\
\hline & Germany & Encarnação et al. (2005) & Seasonal altitudinal sexual segregation \\
\hline & England & Senior et al. (2005) & Seasonal inter- and intra-sex altitudinal segregation \\
\hline & Slovakia & Kaňuch \& Krištín (2006) & Altitudinal sex segregation \\
\hline \multicolumn{4}{|c|}{ Myotis emarginatus } \\
\hline & Germany & Holzhaider \& Zahn (2001) & Male bias at higher elevations \\
\hline \multicolumn{4}{|c|}{ Myotis evotis } \\
\hline & British Columbia, & Grindal et al. (1999) & Altitudinal sex segregation for all species combined, species- \\
\hline & Canada & & specific patterns not presented \\
\hline \multirow{3}{*}{\multicolumn{2}{|c|}{ Washington, USA }} & Thomas (1988) & Only males at higher elevation in one mountain range but not \\
\hline & & & others \\
\hline & & Baker \& Lacki (2004) & Male sex bias at high elevation \\
\hline & Colorado, USA & O’Shea et al. $(2011 a, b)$ & Reproductive females rare at high elevation \\
\hline
\end{tabular}

Myotis formosus ${ }^{1}$

Taiwan

Cheng (2009); Cheng et al.

High-elevation hibernation, summer activity at low elevations 


\begin{tabular}{|c|c|c|c|}
\hline Taxon & Location & References & Nature of data \\
\hline \multicolumn{4}{|c|}{ Myotis lucifugus } \\
\hline & California, USA & Allen (1919) & As Myotis albicinctus; only male captures at high elevation \\
\hline & Colorado, USA & O’Shea et al. $(2011 b)$ & $\begin{array}{l}\text { Female bias at low elevation in summer, male bias at high } \\
\text { elevation in summer }\end{array}$ \\
\hline & South Dakota, USA & Cryan et al. (2000) & Variation in sex bias along altitudinal transect \\
\hline \multirow{2}{*}{\multicolumn{2}{|c|}{ Washington, USA }} & Thomas (1988) & $\begin{array}{l}\text { Only males at higher elevation in one mountain range but not } \\
\text { others }\end{array}$ \\
\hline & & Baker \& Lacki (2004) & Male sex bias at high elevation \\
\hline & Alberta, Canada & Barclay (1991) & Seasonal sex bias at high elevation \\
\hline & British Columbia, & Grindal et al. (1999) & Altitudinal sex segregation for all species combined, species- \\
\hline & Canada & & specific patterns not presented \\
\hline \multicolumn{4}{|c|}{ Myotis myotis } \\
\hline & Switzerland & Jaberg \& Guisan (2001) & Seasonal altitudinal effect in species distribution model \\
\hline & Germany & Holzhaider \& Zahn (2001) & Male bias at higher elevations \\
\hline \multicolumn{4}{|c|}{ Myotis mystacinus } \\
\hline & Germany & Holzhaider \& Zahn (2001) & Male bias at higher elevations, maternity colonies only at lower \\
\hline
\end{tabular}




\begin{tabular}{lll}
\hline Taxon & Location & References \\
\end{tabular}

elevation

Myotis occultus

Colorado, USA O'Shea et al. (2011a)

Myotis ruforniger ${ }^{1}$

Taiwan

Cheng et al. (2010)

Myotis septentrionalis

$$
\text { South Dakota, USA Cryan et al. (2000) }
$$

Myotis thysanodes

$\begin{array}{ll}\text { South Dakota, USA } & \text { Cryan et al. (2000) } \\ \text { Washington, USA } & \text { Baker \& Lacki (2004) }\end{array}$

Myotis volans
California, USA
Allen (1919)
South Dakota, USA
Cryan et al. (2000)

Reproductive females rare at high elevation; radio-tracked

female suspected to be moving downslope from winter to

summer roost

High-elevation hibernation, summer activity at low and high elevation

Variation in sex bias along altitudinal transect

Variation in sex bias along altitudinal transect

Male bias at high elevation

As Myotis longicrus; only male captures at high elevation

Variation in sex bias along altitudinal transect 


\begin{tabular}{|c|c|c|c|}
\hline Taxon & Location & References & Nature of data \\
\hline \multirow{2}{*}{\multicolumn{2}{|c|}{ Washington, USA }} & Thomas (1988) & $\begin{array}{l}\text { Only males at higher elevation in one mountain range but not } \\
\text { others }\end{array}$ \\
\hline & & Baker \& Lacki (2004) & Male bias at high elevation \\
\hline & British Columbia, & Fenton et al. (1980) & Male bias at higher elevation \\
\hline & Canada & Grindal et al. (1999) & $\begin{array}{l}\text { Altitudinal sex segregation for several species combined, did } \\
\text { not present species-specific patterns }\end{array}$ \\
\hline \multicolumn{4}{|c|}{ Myotis watasei $^{1}$} \\
\hline & Taiwan & Cheng (2009) & Hibernate at high elevation, summer at low elevation \\
\hline \multicolumn{4}{|c|}{ Myotis yumanensis } \\
\hline \multirow{2}{*}{\multicolumn{2}{|c|}{ California, USA }} & Grinnell (1918) & Only females and young at low elevation \\
\hline & & Allen (1919) & Only males at high elevation \\
\hline & Washington, USA & Thomas (1988) & Male bias at high elevations \\
\hline & British Columbia, & Fenton et al. (1980) & Male bias at higher elevation \\
\hline & Canada & Grindal et al. (1999) & $\begin{array}{l}\text { Altitudinal sex segregation for several species combined, } \\
\text { species-specific patterns not presented }\end{array}$ \\
\hline
\end{tabular}




\begin{tabular}{llll}
\hline Taxon & Location & References & Nature of data \\
\hline & Slovakia & Kaňuch \& Krištín (2006) & Altitudinal sex segregation
\end{tabular}

Parastrellus hesperus
Arizona, USA
Hoffmeister (1970)
As Pipistrellus hesperus; altitudinal migration suggested but no evidence
Colorado, USA
O'Shea et al. (2011a)
Reproductive females rare at high elevation
Mexico, Honduras $\quad$ Davis (1959)
As Pipstrellus subflavus veraecrucis; museum specimens suggest summer in lowlands and hibernation in high elevation caves and mines

Perimyotis subflavus

Kaňuch \& Krištín (2006)

Holzhaider \& Zahn (2001)

Germany

Pipistrellus nathusii

Germany

Holzhaider \& Zahn (2001)
Altitudinal sex segregation

Male bias at high elevations, maternity colonies only at lower elevation

Male bias at high elevations

Plecotus auritus 


\begin{tabular}{|c|c|c|c|}
\hline Taxon & Location & References & Nature of data \\
\hline & Germany & Holzhaider \& Zahn (2001) & Male bias at higher elevations \\
\hline \multicolumn{4}{|c|}{ Vespertilio murinus } \\
\hline & Germany & Holzhaider \& Zahn (2001) & Male bias at higher elevations \\
\hline
\end{tabular}

\section{MOLOSSIDAE}

Tadarida brasiliensis

Mexico Constantine (1967)

Males move to higher elevations than females, lower elevation

in winter

\section{RHINOLOPHIDAE}

Rhinolophus hipposideros

\section{Austria}

Hutterer et al. (2005)

Winter roosts in mountains, summer roosts in lowlands

\section{PHYLLOSTOMIDAE}

Anoura geoffroyi

Nicaragua

Artibeus concolor

Ecuador
Hutson (2004)

Fraser et al. (2010)
Suggests altitudinal migration, no evidence

No data, just statement of altitudinal migration to track fruit

Artibeus lituratus 


\begin{tabular}{llll}
\hline Taxon & Location & References & Nature of data \\
\hline & Costa Rica & Timm \& LaVal (2000) & Seasonal absence from high-elevation site
\end{tabular}

Artibeus obscurus

Ecuador

Hutson (2004)

Artibeus toltecus

$\begin{array}{ll}\text { Nicaragua } & \text { Fraser et al. (2010) } \\ \text { Costa Rica } & \text { Timm \& LaVal (2000) }\end{array}$

Carollia brevicauda

$\begin{array}{ll}\text { Nicaragua } & \text { Fraser et al. (2010) } \\ \text { Costa Rica } & \text { Timm \& LaVal (2000) }\end{array}$

Chiroderma salvini

Nicaragua

Fraser et al. (2010)

Choeronycteris mexicana

Mexico

Valiente-Banuet et al. (1996,

1997)

Glossophaga soricina

Nicaragua
Fraser et al. (2010)
No data, just statement of altitudinal migration to track fruit

Suggests altitudinal migration, no evidence

Seasonal variation in abundance at high-elevation site

Suggests altitudinal migration, no evidence

Seasonal variation in abundance at high-elevation site

Suggests altitudinal migration, no evidence

Suggests altitudinal migration by bats pollinating flowers

Suggests altitudinal migration, no evidence 


\begin{tabular}{|c|c|c|c|}
\hline Taxon & Location & References & Nature of data \\
\hline \multicolumn{4}{|c|}{ Hylonycteris underwoodi } \\
\hline & Costa Rica & Timm \& LaVal (2000) & Seasonal variation in abundance at high-elevation site \\
\hline \multicolumn{4}{|c|}{ Leptonycteris nivalis } \\
\hline & Mexico & Valiente-Banuet et al. (1997) & Mainly about pollination (possibly by altitudinal migrant bats) \\
\hline \multicolumn{4}{|c|}{ Leptonycteris yerbabuenae ${ }^{2}$} \\
\hline \multirow{3}{*}{\multicolumn{2}{|c|}{ Mexico }} & Herrera-Montalvo (1997) & Only males at high-elevation site \\
\hline & & Valiente-Banuet et al. (1996, & Suggests altitudinal migration by bats pollinating flowers \\
\hline & & 1997) & \\
\hline & SW USA, Mexico & Cockrum (1991) & Seasonal occurrence records across large region \\
\hline & & Rojas-Martínez et al. (1999) & Seasonal captures at high and low elevation \\
\hline \multicolumn{4}{|c|}{ Loncophylla robusta } \\
\hline & Ecuador & Hutson (2004) & No data, just statement of altitudinal migration to track fruit \\
\hline \multicolumn{4}{|c|}{ Micronycteris megalotis } \\
\hline & Ecuador & Hutson (2004) & No data, just statement of altitudinal migration to track fruit \\
\hline \multicolumn{4}{|c|}{ Mimon crenulatum } \\
\hline & Ecuador & Hutson (2004) & No data, just statement of altitudinal migration to track fruit \\
\hline
\end{tabular}




\begin{tabular}{|c|c|c|c|}
\hline Taxon & Location & References & Nature of data \\
\hline \multicolumn{4}{|c|}{ Phyllostomus hastatus } \\
\hline & Ecuador & Hutson (2004) & No data, just statement of altitudinal migration to track fruit \\
\hline \multicolumn{4}{|c|}{ Platyrrhinus brachycephalus } \\
\hline & Ecuador & Hutson (2004) & No data, just statement of altitudinal migration to track fruit \\
\hline \multicolumn{4}{|c|}{ Platyrrhinus helleri } \\
\hline & Ecuador & Hutson (2004) & No data, just statement of altitudinal migration to track fruit \\
\hline \multicolumn{4}{|c|}{ Pygoderma bilabiatum } \\
\hline & Brazil & Esbérard et al. (2011) & Seasonal captures, multiple elevations \\
\hline \multicolumn{4}{|c|}{ Sturnira erythromos } \\
\hline & Argentina & Giannini (1999) & Seasonal captures, multiple elevations \\
\hline \multicolumn{4}{|c|}{ Sturnira lilium } \\
\hline & Argentina & Giannini (1999) & Seasonal captures, multiple elevations \\
\hline & Ecuador & Hutson (2004) & No data, just statement of altitudinal migration to track fruit \\
\hline & Nicaragua & Fraser et al. (2010) & Suggests altitudinal migration, no evidence \\
\hline & Costa Rica & Timm \& LaVal (2000) & Seasonal absence from high-elevation site \\
\hline
\end{tabular}




\begin{tabular}{|c|c|c|c|}
\hline Taxon & Location & References & Nature of data \\
\hline \multicolumn{4}{|c|}{ Sturnira ludovici } \\
\hline & Nicaragua & Fraser et al. (2010) & Suggests altitudinal migration, no evidence \\
\hline \multicolumn{4}{|c|}{ Sturnira mordax } \\
\hline & Costa Rica, Panama & McCarthy et al. (2005) & Speculation of altitudinal migration, no data \\
\hline \multicolumn{4}{|c|}{ Uroderma bilobatum } \\
\hline & Ecuador & Hutson (2004) & No data, just statement of altitudinal migration to track fruit \\
\hline \multicolumn{4}{|c|}{ Vampyressa melissa } \\
\hline & Ecuador & Hutson (2004) & No data, just statement of altitudinal migration to track fruit \\
\hline \multicolumn{4}{|c|}{ Vampyrodes caraccioli } \\
\hline & Ecuador & Hutson (2004) & No data, just statement of altitudinal migration to track fruit \\
\hline \multicolumn{4}{|c|}{ PTEROPODIDAE } \\
\hline \multicolumn{4}{|c|}{ Pteropus giganteus } \\
\hline & Nepal & Hutson (2002) & Suggestion of altitudinal migration in Himalayas \\
\hline \multicolumn{4}{|c|}{ Unspecified taxa/general report } \\
\hline & Global & Hutson et al. (2001) & $\begin{array}{l}\text { IUCN report advising further consideration of altitudinal } \\
\text { migration }\end{array}$ \\
\hline
\end{tabular}




\begin{tabular}{|c|c|c|c|}
\hline Taxon & Location & References & Nature of data \\
\hline & California, USA & Pierson et al. (2001) & $\begin{array}{l}\text { Suggests upslope migration (increased activity by acoustic } \\
\text { monitoring at high-elevation site) to take advantage of late- } \\
\text { season productivity }\end{array}$ \\
\hline
\end{tabular}

${ }^{1}$ There is some taxonomic uncertainty in the status of these species. Myotis ruforniger and Myotis watasei may both be subspecies of Myotis formosus, or M. ruforniger may be a subspecies of $M$. watasei.

${ }^{2}$ L. yerbabuenae was formerly considered a subspecies of Leptonycteris curasoae; L. sanborni is a junior synonym (Wilson \& Reeder, 2005). 
Table 2. Research efforts necessary to document bat altitudinal migration, the nature of the evidence such efforts would provide, and whether such studies provide information at the population or individual level. These research efforts are listed in ascending order of inferential strength. Some efforts will neither confirm nor refute the occurrence of altitudinal migration, rather simply providing data consistent with the possibility of altitudinal migration. More definitive studies (i.e. greater inferential strength) will provide conclusive evidence.

\section{Type of research effort}

Captures/surveys at single

elevation, single season

Captures/surveys at single elevation, multiple seasons

Captures/surveys at multiple elevations, single season

Captures/surveys at multiple elevations, multiple seasons

Mark-recapture, single elevation

Telemetry, single elevation

\section{Mark-recapture at multiple} elevations, multiple seasons

Isotope studies (claws, fur, wing membrane), single

\section{Evidence provided by research effort}

Sex bias (population)

Changes in abundance of one or both sexes (population)

Sexual segregation (population)

Sexual segregation, possibility for detecting temporal variation in migration patterns (population)

Detailed temporal patterns of arrival and departure (individual)

Detailed temporal patterns of timing of departure and possibly direction (individual)

Confirmed migration of at least the marked individuals (individual)

Equivalent to recapture information for multiple individuals, sometimes possible to estimate range where tissue was 
elevation, single season

Isotope studies, single

elevation, multiple years

Telemetry, multiple elevations grown (individual/population)

Temporal consistency in proportion of individuals that migrate (individual/population)

Temporally and spatially detailed movement information (individual) 